Portland State University

PDXScholar

$7-28-2020$

\title{
Intimate Partner Violence Risk Assessment: the Additive Value of Victim Reported Risk
}

Jennifer Joanne Johnson

Portland State University

Follow this and additional works at: https://pdxscholar.library.pdx.edu/open_access_etds

Part of the Criminology Commons, and the Criminology and Criminal Justice Commons Let us know how access to this document benefits you.

\section{Recommended Citation}

Johnson, Jennifer Joanne, "Intimate Partner Violence Risk Assessment: the Additive Value of Victim Reported Risk" (2020). Dissertations and Theses. Paper 5542.

https://doi.org/10.15760/etd.7416

This Thesis is brought to you for free and open access. It has been accepted for inclusion in Dissertations and Theses by an authorized administrator of PDXScholar. Please contact us if we can make this document more accessible: pdxscholar@pdx.edu. 
Intimate Partner Violence Risk Assessment:

The Additive Value of Victim Reported Risk

by

Jennifer Joanne Johnson

A thesis submitted in partial fulfillment of the requirements for the degree of

\author{
Master of Science \\ in \\ Criminology and Criminal Justice
}

Thesis Committee:

Kris Henning, Chair

Christopher Carey

Christopher Campbell

Portland State University

2020 


\begin{abstract}
Intimate partner violence (IPV) affects millions of people in the United States, causing negative generational consequences to the victim and the community. The criminal justice system has increased its preventative strategies to combat this issue through mandatory arrest laws and the use of risk assessment tools for determining the likelihood of offender recidivism. Risk factors included in standardized and actuarial risk assessment tools have been found to be relatively good predictors for violent recidivism.

This study assesses the predictive accuracy of risk factors through bivariate correlations and multiple logistic regression analysis. The risk factors analyzed include demographic information, mental health characteristics, criminal history, suspect-victim relationship characteristics, suspect-victim IPV history, current incident characteristics, and victim-rated risk from the victim interview. A primary question addressed is the additive value of incorporating victim-rated risk for predicting any DV recidivism and violent DV recidivism. The results from this study add to the existing research on Domestic Violence and the predictive strength of the information collected by officers during an incident of IPV.
\end{abstract}




\section{Acknowledgements}

There are many faculty members that have helped me through this journey of completing a thesis. The most notable is Dr. Kris Henning as my chair. Dr. Henning has helped me navigate my way through the long process of writing this thesis and has benefitted me in every step of the way. Although we have faced many challenges during the process of completing this thesis that have forced us to quickly pivot, Dr. Henning has provided ample support and guidance. Dr. Henning has challenged me and allowed me to grow and become a stronger writer and researcher. I am truly thankful for the opportunities to work alongside him.

Another important faculty member that has benefitted me throughout my graduate studies is Dr. Mauri Matsuda. I have been a graduate teaching assistant to Dr. Matsuda for the two years that it took to complete my master's degree. During that time, Dr. Matsuda has given me opportunities to practice my teaching skills and taught me how to become a better researcher along the way. Dr. Matsuda has been an incredible teacher and friend throughout this experience and I am grateful I was able to have her as an instructor.

An important figure to my academic career is Dr. Mark Harmon. Dr. Harmon is an incredible teacher and has taught me everything I know about statistical analysis. For the first time in my academic career, statistical analysis has been exciting. Before meeting Dr. Harmon, math was my least favorite subject, but Dr. Harmon has the ability to make learning statistics enjoyable by taking difficult concepts and making them easily 
digestible. Dr. Harmon's witty humor and approachable attitude has made him an amazing instructor.

Two instructors that have benefitted my writing skills are Dr. Danielle McGurrin and Dr. Christopher Campbell. Dr. McGurrin and Dr. Campbell have pushed me to become a better writer and took the time to explain different methods to improve my writing. Dr. Ryan Labreque and Dr. Brian Renauer are responsible for creating my love for criminological theory. Without the influence of these faculty members, I would not feel as confident writing this thesis and continuing my journey in research. My memories of working with these faculty members are memories that I will cherish. 


\section{Table of Contents}

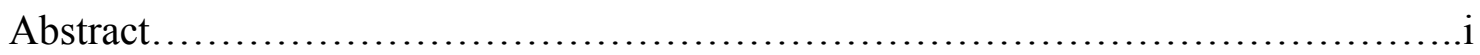



List of Tables.....................................................................

\section{Chapter 1}

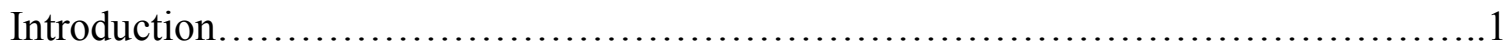

Chapter 2

Literature Review........................................................

Chapter 3

Methods.........................................................................

Chapter 4

Results......................................................................

Chapter 5

Discussion.............................................................. 75

References............................................................... 85 


\section{List of Tables}

Research Question \#1

Table 1: Descriptive Statistics for Suspect Demographics and Bivariate Correlation with DV Recidivism.

Table 2: Logistic Regression Predicting DV Recidivism Using Suspect Demographic Information.

Research Question \#2

Table 3: Descriptive Statistics for Suspect Mental Health History and Bivariate Correlation with DV Recidivism.

Table 4: Logistic Regression Predicting DV Recidivism Using Suspect Mental Health Characteristics.

Research Question \#3

Table 5: Descriptive Statistics for Suspect Criminal History and Bivariate Correlation with DV Recidivism

Table 6: Logistic Regression Predicting DV Recidivism Using Suspect Criminal History

Research Question \#4

Table 7: Descriptive Statistics for Suspect-Victim Relationship and Bivariate Correlation with DV Recidivism

Table 8: Logistic Regression Predicting DV Recidivism Using Suspect-Victim Relationship Characteristics.

Research Question \#5

Table 9: Descriptive Statistics for Suspect-Victim IPV History and Bivariate Correlation with DV Recidivism

Table 10: Logistic Regression Predicting DV Recidivism Using Suspect-Victim IPV History

Research Question \#6

Table 11: Descriptive Statistics for Current Offense Characteristics and Bivariate Correlation with DV Recidivism 
Table 12: Logistic Regression Predicting DV Recidivism Using Current Offense

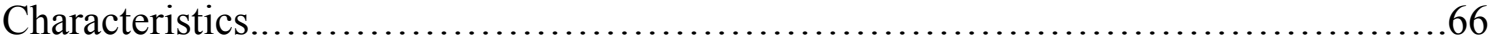

Research Question \#7

Table 13: Descriptive Statistics for Victim-Rated Risk and Bivariate Correlation with DV

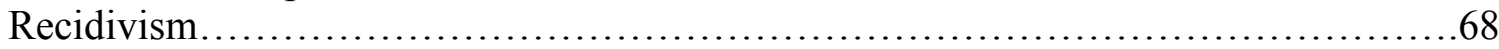

Research Question \#8

Table 14: Logistic Regression Predicting DV Recidivism Using Information from the Incident Report, RMS, and Family Supplemental..................................71

Table 15: Logistic Regression Predicting DV Recidivism Using Information from the Incident Report, RMS, Family Supplemental and Victim Interview (Excluding VictimRated Risk)

Table 16: Logistic Regression Predicting DV Recidivism Using Information from the Incident Report, RMS, Family Supplemental and Victim-Rated Risk from the Victim Interview. .73

Table 17: Logistic Regression Predicting DV Recidivism Using Information from the Incident Report, RMS, Family Supplemental and Victim Interview (Including VictimRated Risk). 


\section{Chapter 1}

\section{Introduction}

Intimate partner violence (IPV) is a term used to describe physical or sexual aggression between current or former intimate partners (Costa, Kaestle, Walker, Curtis, Day, Toumbourou, and Miller, 2015). This form of violence is estimated to affect 1.5 million people annually, generating 4.1 billion dollars in medical costs, victim services, and court expenses in the United States (Kindness, Kim, Alder, Edwards, Parekh, and Olson, 2009). This type of violence has the potential to cause negative generational consequences for all members of society, from adults to children. IPV has been recognized as a public health issue with the effects being known to have long-term negative consequences on the victim and the community, forcing the criminal justice system to create preventative strategies to reduce the rate of IPV.

There has been an increase in preventative strategies pushed forward by multiple facets of the criminal justice system in the form of victim services, advocacy groups, specialized domestic violence units, specialized court services and polices; The most notable change is the implementation of mandatory arrest laws (Bowen, 2011). Mandatory arrest laws state that an officer must arrest the offender when they have probable cause that an offense was committed (Hirschel, Buzawa, Pattavina, and Faggiani, 2007). Using focused deterrence strategies, the criminal justice system can create a responsive plan to identify high-risk offenders and mobilize law enforcement resources toward reducing IPV (Bowen, 2011). Preventative strategies for IPV rely on the 
criminal justice system's understanding of the predictors and risk factors for intimate partner violence perpetration (Costa et al., 2015).

Risk assessment instruments used by law enforcement personnel and professional clinical evaluators are able to estimate the likelihood that an IPV offender will re-offend (Messing \& Thaller, 2013). Empirically tested static and dynamic risk factors have been found to be more accurate predictors for recidivism than professional judgment (Messing \& Thaller, 2013). Victims of IPV have also been found to be generally good evaluators of their own risk, and incorporating multiple risk assessment tools will increase the accuracy for predicting recidivism (Campbell, Webster, and Glass, 2009; Messing \& Thaller, 2013). This research intends to build upon the existing literature on IPV by assessing the additive value of incorporating static and dynamic risk factors from multiple sources. 


\section{Chapter 2}

\section{Literature Review}

The Prevalence and Impact of Intimate Partner Violence

In the United States, the lifetime prevalence of IPV falls between 25 and 35 percent (Messing \& Campbell, 2016). Petrosky, Blair, Betz, Fowler, Jack, and Lyons (2017) found IPV to be responsible for roughly 10,000 homicides between 2003 to 2014, suggesting IPV is responsible for approximately 1,000 homicides yearly. IPV has the potential to cause negative transgenerational consequences for all aspects of society, from adults to children. In an extensive review of longitudinal studies on IPV and childhood exposure, it was discovered that 42 percent of the children in the studies who experienced the psychological and physical trauma of IPV were also perpetrators, and those experiences in childhood were consistent predictors of IPV perpetration in both males and females (Costa et al., 2015). Children who experience violence in their homes are more likely to exhibit similar behaviors as they get older and develop intimate relationships.

The impact of witnessing physical conflict as a child may potentially manifest in future behavioral problems, including aggression and violent offending (Wolfe, Crooks, Lee, McIntyre-Smith, Jaffe, 2003; Holtzworth-Munroe and Stuart, 1994; Murrell, Christoff, and Henning, 2005). Wolfe et al. (2003) and Kitzmann, Gaylord, Holt, and Kenny (2003) found that exposure to IPV in childhood negatively affected academic, emotional, psychological, social, and behavioral functioning. Long and short term effects from previous exposure to IPV may manifest in conduct problems with adverse 
externalizing or internalizing reactions (Wolfe et al., 2003; Kitzmann et al., 2003).

Kitzmann et al. (2003) found that $63 \%$ of children previously exposed to IPV had worse outcomes than children without previous IPV exposure. Exposure to IPV in childhood is also associated with anxiety, depression, and post-traumatic stress disorder symptoms (Trevillion, Oram, Feder and Howard, 2012; Devries, Mak, Bacchus, Child...Watts, 2013; Golding, 1999). The negative consequences of childhood exposure to IPV have been known to be transgenerational.

The transgenerational transmission of violence can be explained through social learning theory, which suggests that children learn how to commit violence by either observing or experiencing violence in the home (Stith, Rosen, Middleton, Busch, Lundeberg, and Carlton, 2000). Violence is learned through direct behavioral conditioning when children learn to imitate an action that is later reinforced in adulthood (Stith et al., 2000). Smith-Marek, Cafferky, Dharnidharka, Mallory... Mendez (2015) found that previous childhood exposure to aggressive strategies increased the likelihood of IPV perpetration and future aggression. This meta-analysis found that children predisposed to aggressive strategies were 2-4 times more likely to use future aggressive strategies (Smith-Marek et al., 2015). These studies suggest that children learn to use aggressive tactics from the people in their environment.

When children are predisposed to violence, they may imitate those behaviors with future relationships they develop. Murrell, Christoff, and Henning (2005) analyzed a correlation between witnessing the target behavior of threatening a person with a weapon as a child and reflecting that same behavior as an adult. The study found that $10 \%$ of the sample who engaged in the target behavior witnessed the act as a child (Murrell et al., 
2005). Murrell et al. (2005) support the notion of observational learning, where children who witness violence in the home often mirror the behavior as an adult. Observational learning stems from social learning theory, which suggests that violent behavior is modeled when learned through violent environments (Murrell et al., 2005; Murrell et al., 2007). Smith-Marek et al. (2015) found a significantly stronger association between previous exposure to IPV in childhood and future aggression in males than females. A meta-analysis on the sex differences in aggression between heterosexual partners found that female perpetration of aggression was higher than males with male perpetration causing more injury to the victim (Archer, 2000; Costa et al., 2015). Previous research has mixed results on the effect of aggressive modeling behavior in males and females. Many studies have found higher rates of aggression in males, while several studies have found higher rates in female populations.

There are both short and long term effects of exposure to violence on mental health. Trevillion et al. (2012) focused on the association between prolonged exposure to IPV in adulthood and the presence of mental disorders. Men and women with a mental disorder were more likely to experience IPV (Smith-Marek et al., 2015). Golding (1999) found significantly higher rates of depression in IPV victims than the general public, with 47.6 percent and 10.2 percent, respectively. The meta-analytic overview from this study suggests that victims of IPV experience depression at the highest rate while in emergency shelters but continue to have higher rates of depression than the general public (Golding, 1999).

In summary, the victims of physical IPV potentially face short and long term physical and mental health consequences after the abuse. IPV has been recognized as a 
public health issue with the effects being known to have long-term negative consequences on the victim and children involved, forcing the criminal justice system to create preventative strategies to reduce the rate of IPV.

\section{The Criminal Justice Response to IPV}

The policy for mandatory arrests is the most noteworthy preventative strategy implemented by the criminal justice system (Bowen, 2011). This policy is highly influenced by the work by a 1980s study at the Minneapolis Police Department by Lawrence W. Sherman, which focused on comparing alternative police responses for incidents of IPV, and their impact on offender recidivism (Sherman, Smith, Schmidt, and Rogan, 1992). This study found that arresting the suspect resulted in a lower risk of recidivism for IPV offenders than on-scene counseling or separation (Sherman et al., 1992). The result of this experiment sparked the criminal justice system's interest in mandatory arrest laws and initiated a series of new studies that tried to replicate the Sherman experiment, named the Spouse Assault Replication Program (SARP) (Maxwell et al., 2002). A meta-analysis using the original data from the SARP experiments had consistent findings with Sherman (1992) with arresting the offender having a reduction in recidivism, but the effect was moderate (Maxwell et al., 2002)

As a result of mandatory arrest laws, there has been an increase in sanctions placed on perpetrators of IPV (Bowen, 2011). The strategy of arresting all primary aggressors for IPV creates a "one size fits all" approach in the criminal justice system. Without careful consideration for variation in offenders, criminal justice strategies may fail to achieve the goal of reducing domestic violence. Previous research studies have found different typologies in IPV offenders. For instance, Holtszworth-Munroe and 
Stuart (1994) found three distinct types of IPV offenders. The first is categorized as a family-only offender. This group is unlikely to commit crimes outside the home and is attributed to the lowest severity of violence (Holtsworth-Munroe and Stuart, 1994). The second group is borderline dysphoric and is characterized as being more likely to have substance abuse problems, moderate to severe violence, and may potentially commit crimes outside the home (Holtzworth-Munroe and Stuart, 1994). The third group is characterized as being generally violent with a high probability of substance abuse problems, an extensive criminal history, violence perpetrated outside the home, and moderate to severe marital violence (Holtzworth-Munroe and Stuart, 1994). A significant criticism of mandatory arrest is the failure to acknowledge the varying types of IPV offenders identified within the previous literature.

While mandatory arrest laws are a method of ensuring certain sanctions for offending, focused deterrence is another tactic used by law enforcement agencies. This strategy uses the fear of swift, certain, and severe sanctions to deter specific criminal behavior (Braga and Weisburd, 2012). The logic behind focused deterrence states that carefully selected high-risk offenders receive concentrated law enforcement attention (Braga and Weisburd, 2012). In High Point, North Carolina, they created the Offender Focused Domestic Violence Initiative, which used focused deterrence policing strategies for IPV. When Sechrist and Weil (2018) reviewed the program, they found a 20\% reduction in DV related calls for service and arrests. Aside from this study, the majority of focused deterrence has been oriented toward gun and gang violence, while IPV has been largely overlooked. With this aspect, we need to do more to identify and respond to high-risk IPV offenders at the policing stage. 


\section{Risk, Need, and Responsivity}

A tool that has been known to be effective in domestic violence programs and correctional institutions is the risk, need, and responsivity principles. These principles are used to make informed decisions regarding the allocation of resources to achieve the many goals of the agencies involved. While the objective of focused deterrence is identifying high-risk offenders, the risk, need, and responsivity principles take a rehabilitative approach toward reducing recidivism. Rehabilitative approaches focus on aspects of the offender that are subject to intervention.

Previous studies have focused on the structural and static demographic information of the offender such as age, race, and gender as an explanation for crime, while current studies have started to shift into understanding the dynamic social and psychological explanations for criminal conduct (Andrews and Bonta, 1998; Farrington, 2003). Static variables explain the differences between individuals that are unchanging while dynamic variables explain the differences within individuals that can change over time or through intervention (Farrington, 2003). Understanding the dynamic, changeable factors within an individual can be best understood through the risk, need, and responsivity principles.

The risk, need, and responsivity principles focus on matching treatment and intervention services to the appropriate offenders. A meta-analysis by Andrews and Dowden (2006) reviewed 225 studies that assessed the effectiveness of implementing the risk, need, and responsivity principles for offenders. The risk principle focuses on the "who needs treatment" and states that services are better suited to offenders at high-risk 
for re-offending instead of low-risk offenders that may not recidivate regardless of services offered (Andrews and Dowden, 2006; Andrews, 1990). The risk principle is implemented to reduce re-offending by delivering effective services to offenders and coordinating those services for the appropriate level of risk. The objective of the risk principle is to reduce offender recidivism through rehabilitative programs offered to high risk offenders (Andrews and Dowden, 2006). When the level of risk is determined, the principle of need and responsivity is established.

The need principle focuses on criminogenic needs or target dynamic risk factors in an offender's life that are empirically linked to criminal activity (Andrews, 1990). The idea of the need principle is to target an individual's characteristics that are changeable to reduce recidivism probability (Andrews, 1990). This is done by assessing the needs of an individual, whether that it is drug or alcohol treatment, anger management, or psychological treatment for mental health.

The responsivity principle focuses on strategies utilized to reduce an offender's criminal behavior. The Andrews and Dowden (2006) meta-analysis suggested strong support for the risk principle when treatment adhered to the principles of need and general responsivity. These results remained strong regardless of the justice context, quality of the study, offender ethnicity, and offender history of violent behavior (Andrews and Dowden, 2006). The risk, need, and responsivity principles have been successful when evaluating risk factors for general criminal behavior. While the general criminal literature has developed separately from IPV research, similar practices have been developed to identify risk factors specifically for IPV offenders to determine the risk for re-offending. 


\section{Risk Factors for IPV}

In risk assessment literature, there are two distinct types of research samples. In community samples, we identify IPV correlations, while criminal justice samples identify risk factors that predict recidivism. Both types of research use static and dynamic variables.

\section{Demographic Variables}

Several research studies have found that age, race, and biological sex are consistently strong predictors for IPV recidivism. Capaldi, Knoble, Shortt, and Kim (2012) found a negative association between age and IPV, indicating that the risk of an offense declines as the offender ages. This finding is consistent with the general literature on IPV perpetration. A meta-analysis consisting of 391 studies found that age had a stronger negative association with offending in men than in women (Spencer, Stith, and Cafferky, 2019). Archer (2000) found a negative association between age and IPV offending, with a higher rate of perpetration from younger males. Several studies on general criminal offending and violent offending have found similar results.

In community samples, Capaldi et al. (2012) found that women and men were equally likely to be IPV perpetrators, with women showing slightly higher rates of physical aggression. A meta-analysis on the sex differences in aggression between heterosexual partners found that female perpetration of aggression was higher than males, with male perpetration causing more injury to the victim (Archer, 2000; Costa et al., 2015). Women were more likely to use an act of physical aggression toward a partner, but 62 percent of the injuries were inflicted by men (Archer, 2000). 
A community sample found that IPV incident rates were approximately two times higher in African American populations in two out of five studies analyzed (Lipsky, Caetano, Field, and Larkin, 2005). In a systematic review of IPV using a sample of 228 studies, they found that IPV is more prevalent among African American and Hispanic populations (Capaldi et al., 2012). Huang, Son, and Wang (2010) found a higher association of IPV with African American populations after controlling for other factors.

\section{Substance Use}

Churcher \& Nesca (2013), reported 12 studies that found a correlation between substance abuse and violent behavior. The finding that substance abuse is correlated with violent offending is consistent with the general literature on violent behavior and in previous meta-analyses conducted on violent offending (Rosenfeld, 2004; Mallory et al., 2016; Capaldi et al., 2012). Stith, Smith, Penn, Ward, and Tritt (2003) found a strong correlation between illicit drug use and physical abuse in a meta-review of 85 studies on IPV. Capaldi et al. (2012) found that the mixture of illicit drugs and alcohol were associated with IPV perpetration. In a meta-review of longitudinal studies focused on alcohol consumption, nine studies found a positive association between alcohol use and IPV (Devries et al., 2013). Spencer et al. (2019) found a positive correlation between drug use and IPV perpetration $(r=.25)$, and Capaldi, Kim, and Pears (2009) found more cases of IPV committed among those who use alcohol or drugs than those who do not.

A study consisting of 328 domestic violence offenders by Johnson (2008) found that offenders with prior alcohol or drug offense were more likely to be re-arrested than offenders who did not have prior alcohol or drug offenses. An offender's history of alcohol and drug use was found to be significantly associated with an increase in risk for 
IPV recidivism (Campbell, Webster, Koziol-McLain, \& Block 2003; White and Chen, 2002). There is general evidence for significant associations between substance use and IPV perpetration and recidivism among domestic violence research.

\section{Threats to Harm and Suicide}

There have been mixed results regarding suicide attempts and threats to harm one's self with IPV perpetration. A history of suicide attempts was found to be a significant predictor for violence against a partner (Kerr and Capaldi, 2011). Coker, Smith, Bethea, King, and McKeown (2000) found a positive association between a history of suicidal behavior and IPV. Seedat, Stein, and Forde (2005) did not find significant associations between suicidal behavior and IPV perpetration. In a metaanalysis of 391 studies, Spencer et al. (2019) found a positive correlation between threatening to harm self and IPV victimization among women.

\section{Criminal History}

Criminal history characteristics have been supported as valid and reliable predictors of recidivism. Sims and Jones (1997) found that the younger the offender was during their first arrest increased the odds of new arrests. A comprehensive review of 24 studies on domestic violence by Morgan (1994) found that younger offenders were more likely to re-offend than older offenders. The research on age and re-offending continued in Olson and Stalans (2001), who found that the age of the first arrest was significantly correlated with arrests for domestic violence offenses.

McEwan, Shea, Nazarewicz, and Senkans (2017) found that criminal history was significantly associated with IPV in a community sample. Stith et al. (2003) found a moderate correlation between having a history of physical abuse and current physical 
abuse. In a criminal justice sample, Williams and Houghton (2004) found that over onethird of domestic violence offenders had previous domestic violence arrests, but the violent re-offending reported by victims exceeded the total recidivism reports in official records, including protective order violations and domestic violence re-offending. Bendlin \& Sheridan (2019) suggest that the odds of severe violence are 2.53 times higher if there was previous violence committed by the offender. Studies by Morgan (1994) and Sims and Jones (1997) found that the more prior criminal offenses there were, the more likely the offender will re-offend.

Churcher \& Nesca (2013) suggested that offenders who have a criminal history or a history of violent behavior are more likely to commit future acts of violence. This predictor's effect size increased from .12 in a previous meta-analysis (Rosenfeld, 2004) to .19 , indicating that criminal history as a risk factor is a more robust predictor of violent behavior. Johnson (2008) suggested that each prior criminal offense increased the odds of re-arrest by 1.2 times. The number of prior arrests has been significantly correlated to recidivism, suggesting that the higher the number of prior arrests an offender has, the more likely they are to re-offend (Morgan, 1994; Sims and Jones, 1997; Olson and Stalans, 2001; Hanson and Wallace-Capretta, 2004; Johnson, 2008; Spencer et al., 2019). Williams and Houghton (2004) found that the frequency of violence in the previous six months was a risk factor for IPV perpetration. Kropp and Hart (2004) and Hilton, Harris, Popham, and Lang (2010) found that extrafamilial violence was a strong predictor of IPV perpetration.

Suspect-Victim Relationship Characteristics 
Hyman, Forte, Mont, Romans, and Cohen (2006) found marital status to be the strongest risk factor for IPV, with unmarried women ten times more likely to report their abuse to law enforcement compared to married women or cohabitating partners. Cui, Durtschi, Donnellan, Lorenz, and Conger (2010) found higher rates of IPV within cohabitating couples than married couples. After controlling for demographic and relationship variables, Slashinski, Coker, and Davis (2003) found that married women were less likely to report abuse than separated partners. Separated women were found to be at higher risk for violence than married women (O'Donnell, Smith and Madison, 2002; Williams and Houghton, 2004). Recent separation was found to be positively associated with IPV $(r=.21)$ (Spencer et al., 2019). Several academics have speculated that married couples are less likely to report their abuse causing a limitation in the research. In contrast, other researchers have suggested that marriage is a protective factor against IPV, similar to having reliable employment and children.

When analyzing risk markers for IPV victimization, Spencer et al. (2018) found that the presence of children and financial stress increased the likelihood of IPV victimization, this finding was also supported in the Smith, Thornton, DeVillis, Earp, and Coker (2003) study. Spencer et al. (2019) also found a positive association with the number of children a victim has and IPV victimization. Shared children and the number of children in the home were found to be positively associated with IPV (Hilton et al., 2010). Offender's use of violence, while the victim is pregnant, is also associated with IPV perpetration (Hilton et al., 2010). The use of lethal threats and the use of weapons were found to be a risk factor for IPV (Hilton et al., 2010; Kropp and Hart, 2004). Victim vulnerability factors have been shown to increase the risk for IPV victimization. 
While there has been extensive research on the offender risk factors for IPV, there is a gap in the research focused on victim characteristics and IPV recidivism. Dutton and Goodman (2005) found an important protective factor against IPV victimization is support and ability for the victim to seek tangible help when necessary. In a meta-analytic review of risk markers for IPV victimization, an offender's power over the victim with the victim being reliant on the offender (e.g., housing, transportation) was positively associated with IPV recidivism (Spencer et al., 2019). Suspect-Victim IPV History

Campbell et al. (2003) found a positive association between the offender's stalking or controlling behavior and an increased risk for IPV recidivism. Stalking behavior can be defined as unwanted phone calls/visits from the offender, spying, or intruding on the victim's privacy or damaging the victim's property. Controlling behavior is defined as the offender attempting to dominate the victim's daily activities. In the Spencer et al. (2019) study, the strongest correlations to IPV were victim injury $(r=.54)$, prior stalking behavior $(r=.40)$, controlling behavior $(r=.31)$, and drug use $(r=.25)$ (Spencer et al., 2019). Williams and Houghton (2004) found that the victim reported escalation in the severity or frequency of violence committed by the offender was a valid predictor of IPV.

\section{Protective Order Violations}

A meta-analysis on the effectiveness of protective orders for reducing domestic violence offender recidivism found that protection order violations were reduced when used in conjunction with other protective measures, including arresting the offender (Cordier, Chung, Wilkes-Gillan, and Speyer, 2019). The meta-analysis had 15 studies 
that used victim reported protection order violations, seven studies that relied on police record for a violation, and three studies that have combined sources for measuring protection order violations. The results of the study showed that violations of protective orders were lower in offenders that had no prior criminal history (Cordier et al., 2019). From these results, one might infer that violations of protective orders are associated with an increased risk of recidivism.

The meta-analysis used multiple studies that assessed the overall effectiveness of protective orders. Carlson, Harris, and Holden (1999) reported a significant decrease in physical violence committed by the offender. Holt, Buckley, and Whelan (2003) suggested a decrease in offender contact, threats with a weapon, and injury reported by the victim. McFarlane, Malecha, Gist, Watson... and Smith (2004) found a decrease in violence and harassment committed by the offender after an 18 month follow up with the victim once a protective order was put in place. All three studies suggested a positive outcome after the application of a protective order.

\section{Victim-Rated Risk}

Goodman et al. (2000) used the variables recorded in a previous risk assessment instrument called the Danger Assessment to assess their predictive accuracy for shortterm recidivism and found that victim-rated risk was a strong predictor for IPV recidivism. Victim-rated risk is a score collected from the victim interview after the index incident with information on the offender and their history of violent behavior. Victims of IPV are generally good evaluators of their own risk, and incorporating multiple risk assessment tools have been suggested to increase the accuracy for predicting recidivism (Campbell et al., 2009; Messing \& Thaller, 2013). Weisz, Tolman, and Saunders (2000) 
found victim-rated risk to have the greatest bivariate association to recidivism with victims having strong predictive accuracy. Hilton et al. (2010) found victim-rated risk to be a strong predictor for IPV.

Heckert and Gondolf (2004) found that the inclusion of risk factors with victimrated risk was the best predictor for the outcome. In a critical review of previous studies on DV, Cattaneo et al. (2007) found that 66 percent of victims were able to assess their risk accurately. Studies have shown that victims of IPV have been generally good evaluators of their own risk.

While using static factors has been reliable in their ability to predict risk, incorporating dynamic variables and victim-rated risk may improve the accuracy of prediction. A meta-analysis consisting of 131 studies combined multiple static and dynamic risk factors to determine the strongest predictors of adult recidivism (Gendreau et al., 1996). Using risk factors from the offender's criminal history, demographic information, substance use history, and criminogenic needs, they found that combining multiple risk factors created a better predictive model for adult recidivism (Gendreau et al., 1996). Combining risk factors for stronger predictive accuracy can be seen in risk assessment instruments.

\section{Risk Assessment Instruments}

Risk assessment instruments used by law enforcement personnel, victim advocates, and mental health professionals seek to estimate the likelihood that an IPV offender will re-offend (Messing \& Thaller, 2013). These risk assessment instruments use empirically tested risk factors for IPV and calculate which offenders are at a higher risk to recidivate. Due to the influence that risk assessment has on the offender, victim, 
criminal justice practices, and policymakers, it is imperative that risk assessment instruments are accurate, easy to understand, easy to implement, and empirically validated (Hanson, 2009). Risk assessment tools have evolved from unstructured professional judgment to highly standardized assessments or actuarial measures, including empirically tested static and dynamic risk factors.

Risk assessments have been used across disciplines and practices ranging from criminal justice officials to mental health professionals. The use of risk assessments has evolved through generations. The first-generation of risk assessment tools primarily used professional clinical judgment for determining who would be most likely to re-offend. The main concerns with this generation of risk assessment include the validity and reliability of relying on the arbitrary judgment of professionals conducting the assessment (Bonta, 1996). The unclear fairness and accountability of using professional judgment in the first-generation changed into the second generation of risk assessments using structured and standardized assessments (Hanson, 2009).

The second-generation of risk assessment focused on using statistically significant risk factors. Using these empirically tested risk factors increased the fairness with the decision-making, but not all of the factors were supported with theory (Hanson, 2009). A weakness in the second-generation was the use of only static factors, which limited the utility of the risk assessment (Hanson, 2009). These limitations were addressed in the third generation.

The third-generation included dynamic risk factors to increase the utility of the risk assessment tool. The incorporation of dynamic risk factors increased the predictive accuracy of the risk assessment (Flores, Lowenkamp, Smith, and Latessa, 2006) and 
increased the utility by allowing for target intervention instead of relying solely on the risk assessment to inform supervision. When comparing clinical judgment and actuarial methods, some studies have found that actuarial methods are better predictors of general violence than clinical judgment (Grove, Zald, Lebow, Snitz, and Nelson, 2000).

Risk assessment instruments have been used across disciplines and specialized to target populations, including IPV. The most commonly used risk assessment instruments include the Ontario Domestic Assault Risk Assessment (ODARA), the Spousal Assault Risk Assessment (SARA), the Revised Domestic Violence Screening Instrument (DVSIR), and the Danger Assessment (DA). Most of the risk assessment tools used for IPV are from the third generation.

The ODARA is an actuarial risk assessment instrument scored using criminal case files that are used to predict the risk of recidivism for offenders of IPV and comprise 13 variables that are coded dichotomously (Hilton, Harris, Rice, Lang, Cormier, and Lines, 2004). The ODARA risk assessment tool is used to predict male-to-female marital violence and is meant to be readily accessible to law enforcement officers. This instrument assesses an offender's prior criminal history, current and prior domesticviolence related assaults, children involved in the relationship, and the characteristics of the victim (Hilton et al., 2004). The initial study used 589 offenders located in Ontario, Canada, with information from incident reports filed by police officers that indicated physical contact between cohabitating intimate partners and found a strong predictive accuracy with the variables in the ODARA (Hilton et al., 2004). A later study found that the predictive accuracy of the ODARA was stronger than the DV or SARA (Hilton et al., 2010). 
The DVSI is scored using criminal case files and is used by criminal justice officials to determine which offenders should be held or released before trial. This risk assessment tool was developed by the Colorado Department of Probation Services with input from DV researchers, probation officers, judges, attorneys, and victims. The DVSI focuses on using risk scores ranging from 0-30 to assess the risk-to-victim and risk-toothers (Williams, 2012). This risk assessment instrument is applicable across the various types of perpetrators, family dynamics, and relationships (Williams, 2012). This tool has 12 items that focus on information regarding the extrafamilial and DV criminal history of the offender, employment status, recent separation, and the presence of children during the index offense. A study using 14,970 assessments between 2004 and 2005 suggested the DVSI was a good predictor for recidivism (Williams and Grant, 2006).

The SARA risk assessment was developed as a guideline for professionals within the DV realm to assist in predicting recidivism and treatment strategies. The SARA risk assessment instrument uses 20 items scored on a three-point scale, which are broken up into four sections: Criminal history, psychological adjustment, spousal assault history, and current offense (Messing \& Thaller, 2013). There is a combination of static and dynamic factors in a two-part segment. The first part has ten factors focused on general violence, while the second part focuses on IPV specifically. Based on interviews with the victim or the offender, the SARA is information collected from criminal case files and used for violence prevention (Messing \& Thaller, 2013). The SARA risk assessment uses clinically proven dynamic risk items to predict IPV and has been found to be effective in predicting recidivism (Olver and Jung, 2017). 
The DA is administered to a victim of intimate partner violence either by selfscoring the risk factors or with an evaluator in the healthcare profession, with the purpose of predicting the lethality risk of the victim and empowering the victim to take precautions for their safety (Messing and Campbell, 2016). The items on the DA were selected from interviewing battered women, shelter workers, law enforcement officers, and clinical experts. The DA is broken up into two parts. The first part is a calendar where the victim documents the abuse suffered from their partner to determine if there is an escalation in the frequency or severity of abuse. The second part assesses incidents of past abuse and evaluates 15 risk factors present in the last 12 months; the 15 risk factors are then weighted and used to determine the level of lethality risk for the victim (Campbell, Webster, and Glass, 2009). These 15 risk factors include static variables and dynamic variables about the offender that help the victim determine risk, the higher the score generates a higher risk to the victim (Messing and Campbell, 2016). A limitation of this risk assessment is the limited access to victim information by law enforcement officers. Risk assessment is more effective when information is easily accessible. In a study using 310 victims of homicide (victim proxy used for information), 194 victims of attempted femicide, and 414 victims of abuse, it was found that victims were generally good evaluators of their own risk and were able to predict re-assault (Campbell et al., 2009).

In a recent meta-analysis, the ODARA had the highest predictive accuracy with a mean area under the curve (AUC) of .690, followed by the DA with a mean AUC of .657, the SARA with .643, and the DVSI with .611 (Van der Put, Gobbles, and Assink, 2019). This study showed that actuarial risk assessment methods had an overall AUC effect of 
.657, while structured clinical judgment assessments scored slightly over chance with an AUC of .580 (Van der Put et a., 2019). Before using empirically tested risk assessment instruments, the predicted risk of an offender re-offending relied solely on the judgment of the law enforcement officer. The arbitrary nature of relying on the judgment of the law enforcement officer makes it difficult to predict recidivism. Combining empirically tested static and dynamic risk factors are more accurate predictors for recidivism.

\section{The Current Study}

The current study uses data from the Record Management System (RMS), current offense incident report, Family Violence Supplemental Form, victim interview, and victim-rated risk to identify predictors of DV recidivism. The RMS contains information from the suspect's criminal history while the incident report contains the suspect's demographic information. The DV supplemental form includes information collected by the victim regarding if children were present, the characteristics of their relationship, and the current offense. The victim interview collects information on the victim-suspect IPV history, including the victim's rated risk. This study's main research question assesses the additive value of including victim-rated risk for predicting IPV recidivism. The analyzed variables include demographic information, suspect mental health history, suspect criminal history, suspect-victim relationship characteristics, suspect-victim DV history, current incident characteristics, and victim-rated risk from the victim interview supplied in the family supplemental form. Using bivariate correlation analysis and multivariate logistic regression analysis, I assess these risk factors' predictive strength and the added value of incorporating victim-rated risk in the model. This study adds to the existing research and informs police agencies on the predictive strength of the information 
collected by officers during an IPV incident. The current study addresses eight general research questions (RQs) regarding the prediction of recidivism among IPV suspects. The questions and corresponding hypotheses are documented below.

$\boldsymbol{R Q}$ 1: Are the suspect's demographic characteristics (e.g., age, race, sex) individually and collectively predictive of DV recidivism?

Hypothesis 1: Based on prior research, I hypothesize that age will be negatively correlated with recidivism, while African Americans and Hispanics will have higher rates of $D V$ recidivism.

Several studies have found a correlation between age and criminal offending. Capaldi et al. (2012) and Spencer et al. (2019) found a negative association between age and IPV offending. While the general public perception of sex and IPV suggests a higher prevalence in males, several studies have found higher rates of aggression in females with males causing more injury (Archer, 2000; Costa et al., 2015). Cattaneo and Goodman (2005) found 1 out of 5 studies with White being positively associated with IPV and 3 out of 12 studies with the prevalence of IPV being higher in African American populations. Given the results of these studies, I would expect to see a negative association between age and IPV and a positive association between IPV and the female population.

RQ 2: Are aspects of the suspect's mental health history (e.g., substance abuse history, flagged as suicidal, lethal threats to self) individually and collectively predictive of recidivism?

Hypothesis 2: Based on prior research, I hypothesize that the suspects' mental health history (substance use, flagged as suicidal, lethal threats to self) will be positively correlated with DV recidivism. 
A meta-analytic review found 12 studies that suggested a correlation between substance abuse and violent behavior (Churcher and Nesca, 2013). Stith et al. (2003) reviewed 85 studies and found an association between drug use and physical abuse. A positive correlation was found between IPV victimization and threatening to harm oneself (Spencer et al., 2019). A few studies have found a link between suicidal behavior and IPV perpetration (Kerr and Capaldi, 2011; Coker et al., 2000) while other studies did not (Seedat et al., 2005). Previous literature leads us to believe that I will see a positive correlation between a history of substance abuse and DV recidivism.

RQ 3: Are aspects of the suspects' criminal history (e.g., age $1^{\text {st }}$ suspect, prior arrests, prior violent offenses, prior $D V$, prior extrafamilial violence) individually and collectively predictive of $D V$ recidivism?

Hypothesis 3: Based on prior literature, I hypothesize that criminal history factors (e.g., age $1^{\text {st }}$ suspect, prior arrests, prior violent offenses, prior DV, prior extrafamilial violence) will be positively correlated with $D V$ recidivism. No specific hypothesis is offered for suspects being flagged for DV or eluding/resisting arrest due to a lack of prior research.

Numerous studies have found an association between the age of first arrest and new offenses (Sims and Jonesm 1997; Morgan, 1994; Olson and Stalans, 2001). These studies also found that the higher count of prior offenses caused a higher risk of reoffending. Williams and Houghton (2004) suggested that an increase in the frequency of violence significantly increased the risk of future violence. The findings from multiple studies lead us to believe that criminal history will be a strong predictor for recidivism. 
RQ 4: Are the suspect-victim relationship characteristics (e.g., children, pregnant victim, relationship status, victim vulnerability factors) individually and collectively predictive of DV recidivism?

Hypothesis 4: Based on several studies, I hypothesize that the presence of children and victim pregnancy will be positively correlated with recidivism. I also hypothesize that currently separated couples and the presence of victim vulnerability factors (reliant on the suspect for housing or transportation) will be positively correlated with $D V$ recidivism.

Several studies have found married couples to be at higher risk for IPV than nonmarried partners or cohabitating partners. Academics have speculated why we see this finding in research studies, and some have suggested it is due to unmarried women being more likely to report their abuse to law enforcement (Hyman et al., 2006; Slashinski et al., 2003). Hilton et al. (2010) found an association between shared children, the number of children living with the victim, and the use of violence while the victim is pregnant with IPV perpetration. The suspect's power over the victim was also indicated to be a risk factor for IPV (Spencer et al., 2019). The previous literature suggests that I will see a positive association between suspect-victim relationship characteristics with DV recidivism and violent DV recidivism.

RQ 5: Are characteristics of the suspect-victim IPV history (e.g., lethal threats, assault while the victim is pregnant, escalating violence, recent separation, controlling, or stalking behavior) individually and collectively predictive of DV recidivism?

Hypothesis 5: Based on prior research, I hypothesize that suspect-victim IPV history factors (e.g., lethal threats, assault while the victim is pregnant, escalating 
violence, recent separation, controlling, or stalking behavior) will be positively correlated with $D V$ recidivism.

An offender's controlling or stalking behavior against one's partner has been found to be positively correlated with IPV recidivism (Campbell et al., 2003; Spencer et al., 2019). The escalation in frequency and severity of violence has also been positively correlated with recidivism (William and Houghton, 2004). The findings from these studies suggest that I will see a positive association between suspect-victim IPV history and DV recidivism.

RQ 6: Are the current offense characteristics ( e.g., violent offense, weapon used, protective order violation, force used by officers, children witnessed, lethal threats, victim choked, victim injury, recent substance use) individually and collectively predictive of $D V$ recidivism?

Hypothesis 6: Based on previous studies, I hypothesize that current offense characteristics (e.g., violent offense, weapon used, protective order violation, children witnessed, lethal threats, victim choked, victim injury, recent substance use) will be positively correlated with DV recidivism. Due to a lack of prior research, I will be analyzing force used by officers for exploratory purposes.

The characteristics of the index offense carry a variety of information. I can assess information regarding the victim, the suspect and the methods that were used during the incident. A previous study found current offense characteristics like recent separation, victim injury and drug use to be positively correlated with IPV. The use of threats and weapons during an offense have been found to be a risk factor for IPV (Hilton et al., 2010; Kropp and Hart, 2004). Noted previously, having a criminal history was found to 
be strongly associated with IPV recidivism. Cordier et al. (2019) found lower rates of protective order violations in the index offense in offenders with no prior criminal history. In regard to previous research, I believe I will have a positive correlation between the current offense characteristics and DV recidivism.

$\boldsymbol{R Q} 7:$ Is the victim's rated risk individually and collectively predictive of DV recidivism?

Hypothesis 7: Based on prior research, I hypothesize that victim's rated risk will be positively correlated with DV recidivism.

Previous research has found victim-rated risk to be an accurate predictor for IPV recidivism with victims being good evaluators of their own risk (Goodman et al., 2000; Campbell et al., 2009; Messing and Thaller, 2013). The findings from previous literature leads me to believe that victim-rated risk will be an accurate predictor for DV recidivism. $\boldsymbol{R Q}$ 8: Is information collected from the incident report, RMS, family supplemental and victim interview collectively predictive of DV recidivism?

$\boldsymbol{R Q} \mathbf{8 a}$ - What is the overall predictive utility obtained from the incident report, RMS, and family supplemental?

$\boldsymbol{R} \mathbf{Q} \boldsymbol{B}$ - What is the overall predictive utility obtained from the incident report, RMS, family supplemental and victim interview (excluding victim-rated risk)? $\boldsymbol{R Q} \mathbf{8 c}-$ What is the overall predictive utility obtained from the incident report, RMS, family supplemental and victim-rated risk?

$\boldsymbol{R Q} \mathbf{8 d}$ - What is the overall predictive utility obtained from the incident report, RMS, family supplemental, and victim interview including victim-rated risk? 
Hypothesis 8: Based on prior literature, I hypothesize that the greatest predictive utility will be from the combination of information from the incident report, RMS, family supplemental, and victim interview (including victim-rated risk).

The Olver and Jung (2017) study found that combining two or more risk assessment instruments increased their ability to predict recidivism with different risk assessment scales providing differing abilities for predicting recidivism. In a metaanalysis, the victim-rated risk assessment approach produced a mean AUC of .637, falling slightly behind the approaches that mostly use static variables but scoring higher than the structured clinical approaches (Van der Put et al., 2019). This meta-analysis showed that victim-rated risk had a higher predictive accuracy than structured clinical approaches.

The ODARA consists of mainly static variables, while the DA consists of mainly dynamic variables including drug and alcohol use, stalking behavior, controlling behavior, and the increase in frequency and severity of violence. Both risk assessment instruments wielding a high mean AUC (Van der Put et al., 2019). When analyzing the risk factors collected from the incident report, RMS, supplemental form and victim interview, I will be assessing the additive value of including victim-rated risk to the model.

As noted previously, many of the items on existing IPV risk assessment scales are largely static in nature and readily available in law enforcement databases. To the extent that these factors individually and collectively predict IPV recidivism, agencies may be able to forgo the collection of supplemental data. Use of standardized factors may also 
facilitate the automation of a risk assessment tool, resulting in considerable time savings and improved predictive accuracy (Duwe \& Rocque, 2017). 


\section{Chapter 3}

\section{Methods}

Sample. Data for this current study were provided by a mid-size western city. Criminal incidents flagged as domestic-related between $03 / 15 / 2008$ to $08 / 01 / 2010$ were extracted from the police RMS. Cases including sexual assault or homicide were excluded from our dataset. This resulted in 11,369 cases as a starting point.

Separately stored from the RMS, the data from the family supplemental form was entered periodically by the interns working in the DV unit. Interns were instructed to access every other or every fourth supplemental form when it was available, but this changed over time due to other demands of their time. Once the supplemental forms were accessed, the information was entered into an MS Access database.

We included supplementals that were either "full" or "partially complete" reducing our sample to 2,368. A full supplemental consisted of no more than 5 out of 27 items missing. A partial supplemental consisted of 6 to 26 items missing. Our sample included current or former heterosexual or same-sex partners, but same-sex partners only included 70 cases. After excluding cases with non-intimate relationships, I had a final sample of 1,915 cases.

\section{Measures}

Recidivism

DV Recidivism was defined as any new police report listing the suspect in a new criminal report flagged as DV. Recidivism included arrest and no-arrest cases in the index offense. No arrest was made in 39.4 percent of the cases despite having a mandatory arrest law. The follow-up period was three years, and I excluded re-offenses 
on the same day as the index crime. A range of violent, property, and public order offenses applied as long as the incident was flagged as "DV". Recidivating events did not have to involve the victim from the original index offense.

Violent DV recidivism was defined as any new police report listing the suspect in a new criminal report including a violent offense and flagged as DV. The follow-up period was three years, and I excluded re-offenses on the same day as the index crime. The flagged offenses included aggravated assault, simple assault, assaulting an officer, murder or attempted murder, bomb threats, child abuse (physical abuse), restraining/stalking order violations, compelling prostitution, physical abuse of elderly/disabled, drive-by-shooting, forcible rape, gang shooting, kidnapping, road rage, robbery, sexual offense (excluding statutory), stalking, threats or intimidation. Recidivating events did not have to involve the victim from the original index offense.

\section{Demographic Factors}

Three demographic variables were collected from the incident report. The current age of the suspect was a continuous variable calculated from the suspect's date of birth and the current incident date. Race was recorded as White, Black, Hispanic, or other. Sex was dichotomously coded as female or male.

\section{Suspect Mental Health History}

Several aspects of the suspects' mental health history were recorded from police records. The count of prior alcohol/drug offenses were coded both as a continuous variable and dichotomized $(\mathrm{yes}=1 / \mathrm{no}=0)$. Other variables for the suspect's mental health history were dichotomized. The suspect's history of alcohol problems or drug problems and threats of self-harm was determined from the victim interview. Police officers can 
document if a suspect has a history of self-harm or mental health problems using a flag in the RMS. I used this flag as a dichotomous indicator of risk for self-harm.

\section{Criminal History}

The criminal history of the suspect was primarily from the RMS. The age at first suspect was the age at which the person was first listed as a suspect in RMS. The count of prior arrests was the number of prior arrests listed in RMS for the current suspect. This variable was also analyzed as a dichotomized (yes $=1 /$ no $=0$ ) factor. The count of violent offenses was the number of prior arrests with a violent offense listed in the RMS for the current suspect. This variable was analyzed as a dichotomous (yes $=1 / \mathrm{no}=0$ ) factor. The count of DV reports was the number of reports flagged as DV for the current suspect listed in the RMS and was analyzed as a dichotomous (yes $=1 /$ no $=0)$ factor. The count of prior DV reports in the last year was the count of reports flagged as DV or family disturbance with the current suspect in the past 365 days of the current offense. This variable was analyzed as a dichotomized $(y e s=1 /$ no $=0)$ factor. Police officers can document if a suspect is at high risk for DV using a flag in the RMS. I analyzed the DV flag as a dichotomous $(\mathrm{yes}=1 / \mathrm{no}=0)$ factor. The elude/resist arrest flag was also dichotomized (yes $=1 / \mathrm{no}=0$ ) and used to determine if the suspect had a history of evading or resisting arrest by police officers. Violence outside the home was the only variable in this group from the victim interview. This variable was analyzed as dichotomous $(\mathrm{yes}=1 / \mathrm{no}=0)$ and was determined by the victim if the suspect had a history of violence outside of the home.

Suspect-Victim Relationship 
The suspect-victim relationship characteristics were all from the family supplemental form. The number of children was recorded as the count of children living with the victim and was also analyzed as a dichotomized $(\mathrm{yes}=1 / \mathrm{no}=0)$ factor. Shared children determined if the suspect and victim shared any children and was analyzed as a dichotomous (yes $=1 / n o=0$ ) factor. In the index offense, I recorded if the victim was currently pregnant and analyzed this factor dichotomously $(\mathrm{yes}=1 / \mathrm{no}=0)$. I determined if the suspect and victim were currently married and analyzed the factor as dichotomous ( $(y e s=1 / n o=0)$. I determined if the suspect and victim were currently separated/divorced during the index offense and analyzed the factor as dichotomous (yes $=1 / n o=0$ ). I analyzed victim vulnerability factors by determining if the victim was dependent on the suspect for housing and analyzed this by a dichotomized (yes $=1 / \mathrm{no}=0$ ) factor. I determined if the victim was dependent on the suspect for transportation and analyzed this as a dichotomized (yes $=1 /$ no $=0$ ) factor.

\section{Suspect-Victim DV History}

All predictors from suspect-victim IPV history were collected from the victim interview. I determined if any lethal threats were made to the victim or the kids by asking "does [suspect] threaten to kill himself/herself, you, your children, or other family members?" and when the victim said "yes" they were asked to specify whom the threats were made to. I excluded threats to self and combined threats toward the victim or kids. This was analyzed as a dichotomized (yes $=1 / \mathrm{no}=0$ ) factor. I determined if the suspect ever assaulted the victim while pregnant and was analyzed as a dichotomized (yes $=1 / \mathrm{no}=0$ ) factor. I determined if there was an escalation in frequency or severity of violence by asking the victim "has [suspect]'s violence toward you increased in severity 
or frequency over the past year?" and analyzed this factor dichotomously (yes=1/no=0). I determined if the suspect and victim were recently separated by asking the victim, "have you and [suspect] recently separated or ended your intimate relationship?" and analyzed this factor dichotomously $(\mathrm{yes}=1 / \mathrm{no}=0)$. Controlling behavior from the suspect was determined by asking the victim, "does [suspect] try to control your daily activities (what you can do, who you see, where you go)?" and analyzed this factor dichotomously (yes $=1 /$ no $=0$ ). Stalking behavior was determined by asking the victim, “does [suspect] follow or spy on you, contact you when you do not want it, or damage your property?" and was analyzed as a dichotomized $(\mathrm{yes}=1 / \mathrm{no}=0)$ factor.

\section{Current Offense Characteristics}

Whether the index incident involved a violent offense was listed in the RMS. The use of weapons during the index incident was also listed in the RMS. The RMS listed whether a protective order violation was involved in the index incident. Whether the officers used force during the incident was listed in the RMS. The officer was asked to determine whether any children witnessed the incident and document the information in the family supplemental form. The officer was instructed to report if the suspect made lethal threats to anyone and document the information in the supplemental form. The officer was instructed to record if the victim was choked during the index incident and report the information in the supplemental form. The officer was instructed to report if the victim received any medical treatment during the index incident and record this information in the supplemental form. The officers were also instructed to report if alcohol or drugs were used by the suspect during the current incident. Victim injury/pain level was measured as a continuous variable from the family supplemental 
form with victims rating their injury from 1 mild pain to 10 severe pain. All variables were analyzed as dichotomous ( $y e s=1 / n o=0$ ) factors.

\section{Victim-Rated Risk}

Victim-rated risk was collected from the victim interview. Officers were instructed to ask the victim, "how likely is [suspect] to assault you again in the next year, from 1 not likely to 10 very likely?" and record the victim's response. Any risk (1 vs. 2 to 10) was analyzed as a dichotomized factor. High risk (1 to 5 vs. 6 to 10 ) was analyzed as a dichotomized factor.

\section{Analytical Technique}

Bivariate correlation analysis was used for each of the predictors to determine the relationship with any DV recidivism and any violent DV recidivism. Multivariate logistic regression models and ROC's were used to assess the combined predictive utility of risk factors within each domain. I assessed statistical significance at the .05 level and removing any insignificant risk factors. When measuring the predictive strength of a risk factor, it is common practice to use the receiver operating characteristic (ROC) and the area under the curve (AUC) (Messing \& Thaller, 2013). I used the predicted probabilities (PRE) from logistic regression to calculate the AUC for each domain. The AUC ranges from .50 (no better than chance prediction) to 1.0 (perfect prediction).

Multivariate logistic regression analyses were used to assess the predictive utility of combining significant predictors from the incident report, RMS, and family supplemental form in group 1 . Group 2 included the variables from group 1 with the addition of significant variables from the victim interview (excluding victim-rated risk) to determine if adding the variables from the victim interview improves the utility of the 
model. Group 3 incorporates the variables from group 1 and includes victim-rated risk, to determine the additive value. Group 4 includes all of the significant predictors, including the victim interview and victim-rated risk to determine the predictive utility of combining all the risk factors. This analytical technique determines the predictive utility of the risk factors collected in the incident report, RMS, family supplemental, and victim interview (including victim-rated risk).

I used the Hanley and McNeil (1983) method for comparing two dependent AUCs. I first calculated the AUCs and standard error for each model, then calculated the correlation coefficient for each model separately for recidivists and non-recidivists. Using this information, I was able to calculate a z-score. Z-scores greater than 1.96 indicates a statistically significant improvement in predicting recidivism. This analytical technique determines the additive value of victim-rated risk and the predictive value of the dynamic variables retrieved from the victim interview for suspect recidivism. 


\section{Chapter 4}

\section{Results}

I initially ran a descriptive analysis of the dependent variables to determine the base rate for any DV recidivism and any violent DV recidivism. Any DV recidivism included a new police report flagged as "DV" listing the same suspect as the index offense. Any violent DV included any new police report flagged as "DV" including a violent offense listing the same suspect as the index offense. Our initial analysis found 34.9 percent of the sample recidivated for any DV, while 30.6 percent recidivated for any violent DV. RQ 1 - Demographics

Our first set of analyses examined research question number 1, regarding the utility of the suspect's age, race, and sex when predicting DV recidivism and violent DV recidivism. Race and gender were dummy coded $(0,1)$ for the correlations and regression analysis, with White and female held out as the referent category in the latter.

As noted previously, most research studies in the general criminology literature find that recidivism is inversely associated with age and that age is usually a strong predictor of re-offending. Age has also been shown to be negatively correlated with recidivism among IPV offenders (Cattaneo and Goodman, 2005). The average age of suspects in the current sample was $34.7(\mathrm{SD}=10.98)$, ranging from 18 to 92 . As shown in Table 1, age was indeed negatively associated with DV recidivism and violent DV recidivism ( $r=-.02$ and $r=-.02$, respectively), but these correlations were not statistically significant $(p<.05)$. Similarly, age did not make a significant contribution in the 
multivariate logistic regression models predicting any DV recidivism and violent DV recidivism (see Table 2).

Research using community samples has found that IPV is more prevalent among some minority groups, including Blacks (AA) and Hispanics. The next set of analyses assesses whether race/ethnicity is also associated with higher risk for IPV recidivism. The current sample consisted of White (54.1\%), Black (31.0\%), Hispanic (9.9\%), and other (5.0\%) suspects, as shown in Table 1. White suspects relative to other racial/ethnic groups were significantly less likely to recidivate for a new DV offense $(r=-.10, p<.01)$ or a new violent DV offense $(r=-.11, p<.01)$. Compared to other racial/ethnic groups, Black (AA) suspects were more likely to recidivate. This includes an increased risk for any new DV offense $(r=.15, p<.01)$ and an increased risk for a new violent DV offense $(r=.16, p<.01)$. Hispanic suspects were found to be less likely to recidivate for any new DV offense or any new violent DV offense, but these correlations were not statistically significant $(p<.05)$. In the multivariate logistic regression analysis shown in Table 2 , the Black (AA) racial/ethnic group made a significant contribution to the multivariate logistic regression model predicting DV recidivism and violent DV recidivism.

Prior meta-analyses on IPV has found that men and women are equally likely to perpetrate physical aggression on an intimate partner, with a few studies showing higher rates for women (Capaldi et al., 2012; Archer, 2000). The current sample had more DV incidents with male perpetrators $(79.0 \%)$ than female perpetrators $(21.0 \%)$. Shown in Table 1, males were more likely to recidivate compared to females. This includes any new DV recidivism $(r=.08, p<.01)$ and any new violent DV recidivism $(r=.08, p<$ $.01)$. Males made a significant contribution to the multivariate logistic regression model 
predicting DV recidivism and violent DV recidivism. The model indicates that compared to female suspects, males have an increased odds for DV recidivism and violent DV recidivism by a factor of 1.51 and 1.57 , respectively.

Combining the three demographic factors in the logistic regression analysis led to statistically significant models for both DV recidivism and violent DV recidivism (see Table 2). Overall, the suspect's demographic information yielded an AUC of .59 for both DV recidivism and violent DV recidivism. The AUC scores are interpreted using the effect sizes established by Rice and Harris (2005), suggesting that demographic factors have a small effect on predicting DV recidivism. 
Table 1.

Descriptive Statistics for Suspect Demographics and Bivariate Correlations with DV Recidivism.

\begin{tabular}{lcccc}
\hline Factors (data source) & $\mathrm{n}$ & $\%$ or M (SD) & $\begin{array}{c}\text { Any DV } \\
\text { Recidivism (r) }\end{array}$ & $\begin{array}{c}\text { Violent DV } \\
\text { Recidivism (r) }\end{array}$ \\
\hline $\begin{array}{l}\text { Age (Incident Rpt.) } \\
\text { Race (Incident Rpt.) }\end{array}$ & 1,897 & $34.74(10.98)$ & -.02 & -.02 \\
$\quad$ White & & & & \\
Black $^{\mathrm{a}}$ & 1,036 & $54.1 \%$ & $-.10^{* *}$ & $-.11^{* *}$ \\
Hispanic $^{\mathrm{a}}$ & 594 & $31.0 \%$ & $.15^{* *}$ & $.16^{* *}$ \\
Other $^{\mathrm{a}}$ & 189 & $9.9 \%$ & -.04 & -.04 \\
Sex (Incident Rpt.) & 96 & $5.0 \%$ & -.04 & -.03 \\
Male & & & & $.08^{\text {a }}$ \\
Female & 1,522 & $79.0 \%$ & $.08^{* *}$ & \\
\hline
\end{tabular}

$* p<.05, * * p<.01, * * * p<.001$.

aDichotomized (no $=0$; yes $=1$ ) for correlations. 
Table 2.

Logistic Regression Predicting DV Recidivism Using Suspect Demographic Information

\begin{tabular}{|c|c|c|c|c|c|c|}
\hline \multirow[b]{2}{*}{ Factors } & \multicolumn{3}{|c|}{ Any DV Recidivism } & \multicolumn{3}{|c|}{$\underline{\text { Violent DV Recidivism }}$} \\
\hline & B & SE & $\operatorname{Exp}(B)$ & B & SE & $\operatorname{Exp}(B)$ \\
\hline Age & -.00 & .01 & 1.00 & -.00 & .01 & 1.00 \\
\hline Race - Black ${ }^{\mathrm{a}}$ & $.62 * * *$ & .11 & 1.86 & $.65^{* * *}$ & .11 & 1.92 \\
\hline Race - Hispanic ${ }^{a}$ & -.13 & .18 & .88 & -.15 & .19 & .86 \\
\hline Race - Other ${ }^{a}$ & -.18 & .24 & .83 & -.06 & .25 & .94 \\
\hline Male $^{b}$ & $.41 * *$ & .13 & 1.51 & $.45^{* *}$ & .14 & 1.57 \\
\hline Constant & $-1.04 * * *$ & .20 & & $-1.26 * * *$ & .21 & \\
\hline-2 Log Likelihood & \multicolumn{3}{|c|}{$2,411.14$} & \multicolumn{3}{|c|}{$2,281.90$} \\
\hline Chi-Squared & \multicolumn{3}{|c|}{$55.81 * * *$} & \multicolumn{3}{|c|}{$57.54^{* * *}$} \\
\hline Nagelkerke R Squared & \multicolumn{3}{|c|}{.04} & \multicolumn{3}{|c|}{.04} \\
\hline AUC & \multicolumn{3}{|c|}{.59} & \multicolumn{3}{|c|}{.59} \\
\hline
\end{tabular}

$* p<.05, * * p<.01, * * * p<.001$.

${ }^{\text {a }}$ Reference group was White. ${ }^{\mathrm{b}}$ Reference group was female. 


\section{RQ 2 - Mental Health History}

Our second set of analyses examined research question number two, regarding the predictive value of the suspect's mental health history for DV recidivism and violent DV recidivism. The mental health history consisted of the count of prior alcohol or drug offenses, having a history of alcohol or drug problems, having a history of making lethal threats toward themselves, and being flagged in the RMS as suicidal.

The general literature in criminology suggests an association between alcohol/drug use and offending (Rosenfeld, 2004; Mallory et al., 2016). Several studies in IPV research have found a correlation between substance use and violent offending (Churcher and Nesca, 2013). This set of analyses assessed whether having a history of alcohol/drug problems increase the risk of recidivism. Shown in Table 3, 41.9 percent of the sample had prior alcohol or drug offense ranging from 1 to 67 alcohol or drug offenses recorded in the RMS. In 51.9 percent of the sample, the victim indicated the suspect had an alcohol problem, and 21.2 percent indicated a drug problem. Consistent with several studies, prior alcohol/drug offenses increased the risk for DV recidivism $(r=$ $.18, p<.001)$ and violent DV recidivism $(r=.19, p<.01)$. The suspect's history of alcohol problems indicated by the victim increased the risk of recidivism for new DV offenses $(r=.05, p<.05)$. Having a history of alcohol problems increased the risk of violent DV recidivism, but this correlation was not statistically significant $(p<.05)$. Consistent with Campbell et al. (2003), the suspect's history of drug problems did increase the risk of DV recidivism $(r=.07, p<.001)$ and violent DV recidivism $(r=.05$, $p<.001)$. Prior alcohol/drug offenses made a significant contribution to the multivariate 
logistic regression model for predicting DV recidivism and violent DV recidivism (see Table 4). The model indicates that for every prior alcohol/drug offense the suspect has, the odds of any new DV offense increases by a factor of 1.05 and increases for any new violent DV offense by a factor of 1.06 . Suspect's history of alcohol or drug problems did not significantly contribute to the model.

There have been mixed results in IPV research regarding suicidal behavior and recidivism. Several studies have found a correlation between making lethal threats to harm oneself and IPV (Kerr and Capaldi, 2011; Coker et al., 2000), while other studies have found no statistically significant correlation (Seedat et al., 2005). This analysis aims to determine if lethal threats to harm themselves and suicidal history is correlated with DV recidivism and violent DV recidivism. In the current sample, 8.1 percent made a lethal threat to self, and 4.3 percent were flagged in RMS as having had previous suicidal behavior. Lethal threats increased the risk of DV recidivism and violent DV recidivism, but these correlations were not significant $(p<.05)$. Being flagged in the RMS as having had previous suicidal behavior increased the risk of any new DV offense $(r=.06, p<$ $.01)$ and any new violent DV recidivism $(r=.07, p<.01)$. Similarly, being flagged as suicidal made a statistically significant contribution to the multivariate logistic regression model, but lethal threats did not (see Table 4). The model indicates that suspects who are flagged as suicidal increases the odds for any DV recidivism by a factor of 1.90 , and any violent DV recidivism by a factor of 2.01 .

The combination of the suspect's mental health history in the logistic regression analysis led to a statistically significant model for DV recidivism and violent DV recidivism (see Table 4). The model generated an AUC of .60 for DV recidivism and .61 
for violent DV recidivism. Although this model does a better job of predicting DV recidivism than the suspect's demographic information, the effect is still small. 
Table 3.

Descriptive Statistics for Suspect Mental Health History and Bivariate Correlation with DV Recidivism.

\begin{tabular}{|c|c|c|c|c|}
\hline Factors (data source) & $\mathrm{n}$ & $\%$ or M (SD) & $\begin{array}{l}\text { Any DV } \\
\text { Recidivism } \\
\text { (r) }\end{array}$ & $\begin{array}{c}\text { Violent DV } \\
\text { Recidivism } \\
\text { (r) }\end{array}$ \\
\hline \# Prior Alcohol/Drug Offenses (RMS) & 1,915 & $1.55(3.96)$ & $.13^{* * *}$ & $.14 * * *$ \\
\hline Any Prior Alcohol/Drug Offense ${ }^{a}$ & 802 & $41.9 \%$ & $.18^{* * *}$ & $.19^{* *}$ \\
\hline \multicolumn{5}{|l|}{ Alcohol Problems (Victim Interview) } \\
\hline$Y_{e s}{ }^{a}$ & 723 & $51.9 \%$ & $.05^{*}$ & .05 \\
\hline No & 669 & $48.1 \%$ & & \\
\hline \multicolumn{5}{|l|}{ Drug Problems (Victim Interview) } \\
\hline$Y_{e s}{ }^{a}$ & 295 & $21.2 \%$ & $.07 * *$ & $.07 * *$ \\
\hline No & 1,097 & $78.8 \%$ & & \\
\hline \multicolumn{5}{|l|}{ Lethal Threats to Self (Victim } \\
\hline$Y_{e s}{ }^{a}$ & 115 & $8.1 \%$ & .04 & .01 \\
\hline No & 1,302 & $91.9 \%$ & & \\
\hline \multicolumn{5}{|l|}{ Flagged Suicidal (RMS) } \\
\hline Yes $^{a}$ & 83 & $4.3 \%$ & $.06 * *$ & $.07 * *$ \\
\hline No & 1,832 & $95.7 \%$ & & \\
\hline
\end{tabular}

${ }^{*} p<.05,{ }^{* *} p<.01,{ }^{* * *} p<.001$.

a Dichotomized (no $=0$; yes $=1$ ) for correlations. 
Table 4.

Logistic Regression Predicting DV Recidivism Using Suspect Mental Health Characteristics.

\begin{tabular}{|c|c|c|c|c|c|c|}
\hline \multirow[b]{2}{*}{ Factors } & \multicolumn{3}{|c|}{ Any DV Recidivism } & \multicolumn{3}{|c|}{ Violent DV Recidivism } \\
\hline & B & SE & $\operatorname{Exp}(B)$ & B & SE & $\operatorname{Exp}(B)$ \\
\hline \# Prior Alcohol/Drug & $.05^{* * *}$ & .02 & 1.05 & $.05 * * *$ & .02 & 1.06 \\
\hline Alcohol Problems & .16 & .12 & 1.12 & .13 & .12 & 1.14 \\
\hline Drug Problems & .20 & .15 & 1.23 & .22 & .15 & 1.24 \\
\hline Lethal Threats to Self & .30 & .21 & 1.35 & -.00 & .22 & .99 \\
\hline Flagged Suicidal & $.64^{* *}$ & .27 & 1.90 & $.72 * *$ & .27 & 2.01 \\
\hline Constant & $-.910 * *$ & .09 & & $-1.10 * *$ & .10 & \\
\hline -2 Log Likelihood & \multicolumn{3}{|c|}{$1,689.28$} & \multicolumn{3}{|c|}{$1,597.28$} \\
\hline Chi-Squared & \multicolumn{3}{|c|}{$29.84 * * *$} & \multicolumn{3}{|c|}{$29.75^{* * *}$} \\
\hline Nagelkerke R Squared & \multicolumn{3}{|c|}{.03} & \multicolumn{3}{|c|}{.03} \\
\hline AUC & \multicolumn{3}{|c|}{.60} & \multicolumn{3}{|c|}{.61} \\
\hline
\end{tabular}

$* p<.05, * * p<.01, * * * p<.001$. 


\section{RQ 3 - Criminal History}

Our third research question regarding the predictive utility of the suspect's criminal history for DV recidivism and violent recidivism was examined in our next analysis. Criminal history comprised of the suspect's age of being first listed as a suspect, count of prior arrests, count of prior violent offenses, count of prior DV reports, count of DV reports within the previous 365 days of the index offense, being flagged for DV in the RMS, being flagged as eluding or resisting arrest in the RMS, and violence outside the home indicated by the victim.

Many earlier studies have found that the age of first arrests as a valid predictor for re-offending (Sims and Jones, 1997). The age of first arrest was also found to be negatively correlated with DV offenses in later studies (Olson and Stalans, 2001). In this sample, the average age of being first listed as a suspect was 24.8(11.38) years old, with ages ranging from 1 to 91 (see Table 5). Similar to several studies, I found the age of first listed as a suspect to be negatively associated with DV recidivism $(r=-.19, p<.001)$ and violent DV recidivism $(r=-.18, p<.001)$. Similarly, the age first listed as a suspect had a significant impact in the multivariate regression model predicting DV recidivism and violent DV recidivism (see Table 6).

Many studies have found the suspect's history of criminal offenses as a valid predictor for future offenses (Sims and Jones, 1997; William and Houghton, 2004). A few studies have found recidivism has been positively associated with the number of prior arrests (Morgan, 1994), previous violent offenses (Bendlin and Sheridan, 2019), and prior DV offenses and their frequency (William and Houghton, 2004; Hilton et al., 2010). In the current sample, 69.7 percent had prior arrests averaging 7.72(14.03), arrests 
ranging from 1 to 179. Shown in Table 5, the number of prior arrests increased the risk of DV recidivism $(r=.24, p<.001)$ and violent DV recidivism $(r=.24, p<.001)$. In the sample, 55.1 percent had previous violent offenses averaging 2.61(4.99), violent offenses ranging from 1 to 59. Previous violent offenses increased the risk of DV recidivism ( $r=$ $.24, p<.001)$ and violent DV recidivism $(r=.25, p<.001)$. Prior DV reports ranged from 1 to 45 with an average of 3.48(5.87) in 61.6 percent of the sample. Having a prior DV report increased the risk of DV recidivism $(r=.30, p<.001)$ and violent DV recidivism $(r=.29, p<.001)$. In the last year, 34.1 percent of the sample had DV reports ranging from 1 to 15 with the average number of DV reports being .70(1.41). The count of DV reports in the last year was positively associated with DV recidivism $(r=.28, p<$ $.001)$ and violent DV recidivism $(r=.27, p<.001)$. Violence outside of the home was indicated by the victim in 21.9 percent of the sample and was positively associated with DV recidivism $(r=.07, p<.01)$ and violent DV recidivism $(r=.09, p<.01)$. Only .6 percent of suspects were flagged for DV in the RMS. Being flagged for DV was positively associated with DV recidivism and violent DV recidivism, but these correlations were not statistically significant $(p<.05)$. Suspects flagged for eluding or resisting arrest $(6.4 \%)$ was positively associations to DV recidivism $(r=.14, p<.001)$ and violent DV recidivism $(r=.15, p<.001)$.

The only variables that made a significant contribution to the multivariate logistic regression analysis for predicting DV recidivism and violent recidivism were the age of first listed as a suspect, count of prior arrests, count of prior DV reports, and count of prior DV reports within the last 365 days (see Table 6). Combining the factors from the suspect's criminal history yielded a statistically significant model for predicting DV 
recidivism and violent DV recidivism. The model generated an AUC of .71 for DV recidivism and .71 for violent DV recidivism. Using the interpretations of Rice and Harris (2005), I can suggest that criminal history yields a large effect for predicting DV recidivism. This model suggested that criminal history is a moderately good predictor for DV recidivism in our sample. 
Table 5.

Descriptive Statistics for Suspect Criminal History and Bivariate Correlation with DV Recidivism.

\begin{tabular}{|c|c|c|c|c|}
\hline Factors (data source) & $\mathrm{n}$ & \% or M (SD) & $\begin{array}{c}\text { Any DV } \\
\text { Recidivism } \\
\text { (r) }\end{array}$ & $\begin{array}{c}\text { Violent DV } \\
\text { Recidivism } \\
\text { (r) }\end{array}$ \\
\hline Age at $1^{\text {st }}$ Suspect (RMS) & 1,915 & $24.80(11.38)$ & $-.19 * * *$ & $-.18^{* * *}$ \\
\hline \# Prior Arrests (RMS) & 1,915 & $7.72(14.03)$ & $.24 * * *$ & $.24 * * *$ \\
\hline Any Prior Arrest ${ }^{a}$ & 1,334 & $69.7 \%$ & $.27 * * *$ & $.25^{* * *}$ \\
\hline \# Prior Violent Arrests (RMS) & 1,915 & $2.61(4.99)$ & $.24 * * *$ & $.25^{* * *}$ \\
\hline Any Prior Violent Arrest ${ }^{a}$ & 1,056 & $55.1 \%$ & $.30 * * *$ & $.29 * * *$ \\
\hline \# Prior DV Reports (RMS) & 1,915 & $3.48(5.87)$ & $.30 * * *$ & $.29 * * *$ \\
\hline Any Prior DV Report ${ }^{a}$ & 1,180 & $61.6 \%$ & $.27^{* * *}$ & $.26 * * *$ \\
\hline \# Prior DV Last Year (RMS) & 1,915 & $.70(1.41)$ & $.28^{* * *}$ & $.27^{* * *}$ \\
\hline Any Prior DV Last Year ${ }^{a}$ & 653 & $34.1 \%$ & $.26 * * *$ & $.25 * * *$ \\
\hline \multicolumn{5}{|l|}{ DV Flag (RMS) } \\
\hline Yes $^{\mathrm{a}}$ & 12 & $.6 \%$ & .01 & .02 \\
\hline No & 1,903 & $99.4 \%$ & & \\
\hline \multicolumn{5}{|l|}{ Elude/Resist Arrest Flag (RMS) } \\
\hline Yes $^{\mathrm{a}}$ & 123 & $6.4 \%$ & $.14 * * *$ & $.15^{* * *}$ \\
\hline No & 1,792 & $93.6 \%$ & & \\
\hline \multicolumn{5}{|c|}{ Violent Outside Home (Victim Int.) } \\
\hline$Y_{e s}{ }^{a}$ & 270 & $21.9 \%$ & $.07 * *$ & $.09 * *$ \\
\hline No & 961 & $78.1 \%$ & & \\
\hline
\end{tabular}

$* p<.05, * * p<.01, * * * p<.001$.

aDichotomized (no $=0$; yes $=1$ ) for correlations. 
Table 6.

Logistic Regression Predicting DV Recidivism Using Suspect Criminal History.

\begin{tabular}{|c|c|c|c|c|c|c|}
\hline \multirow[b]{2}{*}{ Factors } & \multicolumn{3}{|c|}{ Any DV Recidivism } & \multicolumn{3}{|c|}{ Violent DV Recidivism } \\
\hline & B & SE & $\operatorname{Exp}(B)$ & B & SE & $\operatorname{Exp}(B)$ \\
\hline Age of $1^{\text {st }}$ Suspect & $-.02 * *$ & .01 & .98 & $-.02 * *$ & .01 & .98 \\
\hline Prior Arrests & $.02 *$ & .01 & 1.02 & $.02 *$ & .01 & 1.02 \\
\hline Prior Violent Offenses & -.03 & .03 & .97 & -.01 & .02 & .99 \\
\hline Prior DV Reports & $.06^{* *}$ & .02 & 1.06 & $.03 *$ & .02 & 1.04 \\
\hline Prior DV Last Year & $.32 * * *$ & .06 & 1.34 & $.28^{* * *}$ & .06 & 1.32 \\
\hline Elude/Resist Flag & .46 & .28 & 1.58 & .43 & .27 & 1.54 \\
\hline Violent Outside Home & -.02 & .16 & .98 & .08 & .16 & 1.09 \\
\hline Constant & $-.65^{* *}$ & .19 & & $-.83 * * *$ & .20 & \\
\hline -2 Log Likelihood & \multicolumn{3}{|c|}{$1,448.83$} & \multicolumn{3}{|c|}{$1,381.01$} \\
\hline Chi-Squared & \multicolumn{3}{|c|}{$147.83^{* * *}$} & \multicolumn{3}{|c|}{$127.48 * * *$} \\
\hline Nagelkerke R Squared & \multicolumn{3}{|c|}{.16} & \multicolumn{3}{|c|}{.14} \\
\hline AUC & \multicolumn{3}{|c|}{.71} & \multicolumn{3}{|c|}{.71} \\
\hline
\end{tabular}

${ }^{*} p<.05,{ }^{* *} p<.01,{ }^{* * *} p<.001$. 


\section{RQ 4 - Suspect-Victim Relationship}

Our fourth set of analyses examined research question number 4, regarding the predictive value of suspect and victim relationship characteristics. This set of variables consists of the number of children living with the victim, if there are any shared children between the suspect and victim, whether the victim was pregnant during the index offense, whether the suspect and victim are married or currently separated, and whether the victim depends on the suspect for housing or transportation.

Several studies have found a positive association between the number of children in the home and IPV victimization (Stith et al., 2003; Hilton et al., 2010; Spencer et al., 2019). This set of analyses aims to determine if having children in the home increase the likelihood of recidivism. Table 7 shows, 63.0 percent of the sample had children living with the victim ranging from 1 to 3 or more children, averaging 1.12(1.66) children per victim. The number of children living with the victim was not associated with DV recidivism and negatively associated with violent DV recidivism. These correlations were not statistically significant $(p<.05)$. In the sample, 30.7 percent shared children between the suspect and the victim. Having shared children was negatively associated with DV recidivism and violent DV recidivism, but these correlations were not significant $(p<$ $.05)$. The number of children and shared children did not make a significant impact on the multivariate logistic regression analysis predicting DV recidivism and violent recidivism.

Hilton et al. (2019) found a positive association between violence while the victim is pregnant and IPV perpetration. This next analysis seeks to determine if the suspect assaulting the victim while pregnant increases the likelihood of recidivism. During the index incident, only 5.7 percent of victims were known to be pregnant. 
Suspect violence while the victim is pregnant was positively correlated with DV recidivism $(r=.05, p<.05)$ and violent DV recidivism $(r=.04)$ but violent DV recidivism was not statistically significant $(p<.05)$. In the multivariate logistic regression analysis shown in Table 8, victim pregnancy made a significant contribution for predicting DV recidivism but not for predicting violent DV recidivism.

Several IPV research studies have found marital status to be a strong risk factor for IPV with higher reported abuse among nonmarried couples (Hyman et al., 2006). Cui et al. (2010) found a higher prevalence of IPV within cohabitating partners than married couples. This analysis will determine whether relationship status is correlated with recidivism. Married couples consisted of 21.2 percent of the sample, and separated couples consisted of 21.6 percent (see Table 7). Similar to several studies, married couples were negatively associated with DV recidivism $(r=-.08, p<.001)$ and violent DV recidivism $(r=-.08, p<.001)$. In contrast, separated couples were positively associated with DV recidivism $(r=.06, p<.05)$ and violent DV recidivism $(r=.05, p<$ $.05)$. Shown in Table 8 , being married made a significant contribution to the multivariate logistic regression analysis for DV recidivism and violent recidivism while being separated did not contribute to the model.

A victim's dependency on the suspect and the suspect's power over the victim has been found to be positively associated with IPV recidivism (Dutton and Goodman, 2005; Spencer et al., 2019). This analysis uses the victim's dependency on the suspect for housing or transportation to determine if a victim's vulnerability is associated with recidivism. In the sample, 20.1 percent of victims reported being dependent on the suspect for housing, and 7.7 percent reported being dependent on the suspect for 
transportation (see Table 7). Contrary to previous studies cited in the literature review, dependency for housing was negatively associated with DV recidivism and violent DV recidivism, but these correlations were not statistically significant $(p<.05)$. Similarly, dependency for transportation was also negatively associated with DV recidivism $(r=$ $.07, p<.01)$ and violent DV recidivism $(r=-.07, p<.01)$. Shown in Table 8 , dependency on transportation had an impact on the multivariate logistic regression analysis for predicting DV recidivism and violent recidivism, but dependency on housing did not have an impact.

The suspect-victim relationship characteristics generated a statistically significant model and an AUC of .59 for both DV recidivism and violent DV recidivism (see Table 8). The model suggests that the effect is small and does slightly better than chance for predicting DV recidivism. The model suggests suspect-victim relationship characteristics were weak predictors for DV recidivism. 
Table 7.

Descriptive Statistics for Suspect-Victim Relationship and Bivariate Correlation with DV Recidivism.

\begin{tabular}{|c|c|c|c|c|}
\hline Factors (data source) & $\mathrm{n}$ & $\begin{array}{c}\text { \% or M } \\
\text { (SD) }\end{array}$ & $\begin{array}{l}\text { Any DV } \\
\text { Recidivism } \\
\text { (r) }\end{array}$ & $\begin{array}{c}\text { Violent DV } \\
\text { Recidivism } \\
\text { (r) }\end{array}$ \\
\hline Number of Children (Fam Suppl.) & 1,018 & $1.12(1.66)$ & .00 & -.03 \\
\hline Any Children ${ }^{a}$ & 641 & $63 \%$ & -.00 & -.03 \\
\hline \multicolumn{5}{|l|}{ Share Children (Fam Suppl.) } \\
\hline Yes $^{\mathrm{a}}$ & 552 & $30.7 \%$ & -.00 & -.02 \\
\hline No & 1,246 & $69.3 \%$ & & \\
\hline \multicolumn{5}{|l|}{ Victim is Pregnant (Fam Suppl.) } \\
\hline$Y_{e s}{ }^{a}$ & 97 & $5.7 \%$ & $.05 *$ & .04 \\
\hline No & 1,608 & $94.3 \%$ & & \\
\hline \multicolumn{5}{|l|}{ Married (Fam Suppl.) } \\
\hline$Y_{e s}{ }^{a}$ & 406 & $21.2 \%$ & $-.08 * *$ & $-.08 * *$ \\
\hline No & 1,509 & $78.8 \%$ & & \\
\hline \multicolumn{5}{|l|}{ Currently Separated (Fam Suppl.) } \\
\hline$Y_{e s}{ }^{a}$ & 380 & $21.6 \%$ & $.06^{*}$ & $.05^{*}$ \\
\hline No & 1,379 & $78.4 \%$ & & \\
\hline \multicolumn{5}{|l|}{ Dependent-Housing (Fam Suppl.) } \\
\hline Yes $^{\mathrm{a}}$ & 340 & $20.1 \%$ & -.04 & -.04 \\
\hline No & 1,352 & $79.9 \%$ & & \\
\hline \multicolumn{5}{|l|}{ Dependent-Transport (Fam } \\
\hline$Y s^{a}$ & 128 & $7.7 \%$ & $-.07 * *$ & $-.07 * *$ \\
\hline No & 1,537 & $92.3 \%$ & & \\
\hline
\end{tabular}

${ }^{*} p<.05,{ }^{* *} p<.01,{ }^{* * *} p<.001$.

aDichotomized (no $=0$; yes $=1$ ) for correlations. 
Table 8.

Logistic Regression Predicting DV Recidivism Using Suspect-Victim Relationship Characteristics.

\begin{tabular}{|c|c|c|c|c|c|c|}
\hline \multirow[b]{2}{*}{ Factors } & \multicolumn{3}{|c|}{ Any DV Recidivism } & \multicolumn{3}{|c|}{$\underline{\text { Violent DV Recidivism }}$} \\
\hline & B & SE & $\operatorname{Exp}(B)$ & B & SE & $\operatorname{Exp}(B)$ \\
\hline Number of Children & .02 & .07 & 1.02 & -.04 & .12 & .45 \\
\hline Share Children & .11 & .17 & 1.11 & .11 & .17 & 1.12 \\
\hline Victim is Pregnant & $.59 *$ & .29 & 1.80 & .44 & .30 & 1.55 \\
\hline Married & $-.41 *$ & .19 & .67 & $-.40 *$ & .20 & .67 \\
\hline Currently Separated & .20 & .17 & 1.22 & .19 & .18 & 1.21 \\
\hline Victim Depends on Housing & .11 & .20 & 1.12 & .18 & .21 & 1.20 \\
\hline Victim Depends on Transport & $-.85^{*}$ & .33 & .43 & $-1.15^{* *}$ & .38 & .32 \\
\hline Constant & $-.65 * * *$ & .12 & & $-.80 * * *$ & .12 & \\
\hline -2 Log Likelihood & & $1,142.99$ & & & $1,078.09$ & \\
\hline Chi-Squared & & $22.42^{* *}$ & & & $23.15^{* *}$ & \\
\hline Nagelkerke R Squared & & .03 & & & .04 & \\
\hline$A \cup C$ & & .59 & & & .59 & \\
\hline
\end{tabular}

${ }^{*} p<.05,{ }^{* *} p<.01,{ }^{* * *} p<.001$. 


\section{RQ 5 - Suspect-Victim IPV History}

Our fifth set of analyses examined research question number five, regarding the predictive value of suspect-victim IPV history. This set of variables includes lethal threat to victim or kids, whether there is a history of assault while the victim is pregnant, a victim indicated escalation of frequency and/or severity of violence, recent separation, controlling behavior, and stalking behavior committed by the suspect.

A previous study found the use of threats toward the victim to be a risk factor for IPV (Hilton et al., 2010). This analysis aims to determine if the use of lethal threats towards the victim or children is associated with DV recidivism. Shown in Table 9, lethal threats to the victim or kids were present in 15.4 percent of the sample. Lethal threats were positively associated with DV recidivism and violent DV recidivism, but these correlations were not significant $(p<.05)$. Lethal threats did not make a significant contribution to the multivariate logistic regression analysis (see Table 10).

Noted previously, recent separation has been found to be positively associated with IPV (Spencer et al., 2019). Violence while the victim is pregnant has also been reported as being associated with IPV perpetration (Hilton et al., 2010). Shown in Table $9,38.3$ percent of victims reported being recently separated. Victim reported assault while pregnant was only reported in 9.8 percent of the sample. Recent separation was positively associated with DV recidivism and violent DV recidivism, but these correlations were not significant $(p<.05)$. Similarly, violence while the victim was pregnant was positively associated with DV recidivism and violent DV recidivism, but these correlations were also not significant $(p<.05)$. Recent separation and violence 
while pregnant did not significantly contribute to the multivariate logistic regression analysis.

An escalation of the frequency and severity of violence has been reported as a valid predictor for IPV perpetration (Williams and Houghton, 2004). In the sample, 43 percent of the victims reported an escalation in the frequency and/or severity of violence and was positively associated with DV recidivism and violent recidivism, but these correlations were not significant $(p<.05)$. Shown in Table 10 , the escalation of violence did not make a significant contribution to the multivariate logistic regression model for predicting DV recidivism.

Several studies have found that controlling or stalking behavior committed by the suspect has been positively associated with IPV (Campbell et al., 2003; Spencer et al., 2019). This analysis aims to assess whether controlling or stalking behavior committed by the suspect increases the likelihood of recidivism. Shown in Table 9, 27.4 percent of the victim's reported controlling behavior from the suspect, and 26.2 percent reported stalking behavior from the suspect. Contrary to Campbell et al. (2003), controlling behavior was negatively associated with DV recidivism and violent DV recidivism, but these correlations were not significant $(p<.05)$. Stalking behavior was positively associated with DV recidivism and violent DV recidivism, but of these correlations were not significant either $(p<.05)$. Neither controlling behavior or stalking behavior made a significant contribution to the multivariate logistic regression analysis.

Overall, the model suggested a weak predictive utility from the suspect-victim IPV history (see Table 10). The model produced an AUC of .55 for DV recidivism and .55 for violent DV recidivism. Although the model for DV recidivism and violent DV 
recidivism was statistically significant, the AUC score suggests the effect of the model is small and only slightly better than chance for predicting DV recidivism. 
Table 9.

Descriptive Statistics for Suspect-Victim IPV History and Bivariate Correlation with DV Recidivism.

\begin{tabular}{|c|c|c|c|c|}
\hline Factors (data source) & $\mathrm{n}$ & $\%$ or $\mathrm{M}(\mathrm{SD})$ & $\begin{array}{l}\text { Any DV } \\
\text { Recidivism } \\
\text { (r) }\end{array}$ & $\begin{array}{c}\text { Violent DV } \\
\text { Recidivism } \\
\text { (r) }\end{array}$ \\
\hline \multicolumn{5}{|c|}{ Lethal Threats-Victim/Kids (Victim Int.) } \\
\hline Yes $^{\mathrm{a}}$ & 218 & $15.4 \%$ & .01 & .02 \\
\hline No & 1,199 & $84.6 \%$ & & \\
\hline \multicolumn{5}{|c|}{ Assault Pregnant Victim (Victim Int.) } \\
\hline$Y_{e s}^{a}$ & 119 & $9.8 \%$ & .04 & .02 \\
\hline No & 1,097 & $90.2 \%$ & & \\
\hline \multicolumn{5}{|c|}{ Escalating Violence (Victim Int.) } \\
\hline$Y_{e s}{ }^{a}$ & 557 & $43.0 \%$ & .04 & .02 \\
\hline No & 737 & $57.0 \%$ & & \\
\hline \multicolumn{5}{|c|}{ Recent Separation (Victim Int.) } \\
\hline$Y_{e s}{ }^{a}$ & 528 & $38.3 \%$ & .04 & .03 \\
\hline No & 850 & $61.7 \%$ & & \\
\hline \multicolumn{5}{|c|}{ Controlling Behavior (Victim Int.) } \\
\hline$Y_{e s}{ }^{a}$ & 351 & $27.4 \%$ & -.00 & -.02 \\
\hline No & 930 & $72.6 \%$ & & \\
\hline \multicolumn{5}{|c|}{ Stalking Behavior (Victim Int.) } \\
\hline$Y_{e s}{ }^{a}$ & 330 & $26.2 \%$ & .04 & .04 \\
\hline No & 931 & $73.8 \%$ & & \\
\hline
\end{tabular}

${ }^{*} p<.05,{ }^{* *} p<.01,{ }^{* * *} p<.001$.

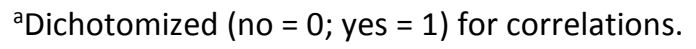


Table 10.

Logistic Regression Predicting DV Recidivism Using Suspect-Victim IPV History.

\begin{tabular}{|c|c|c|c|c|c|c|}
\hline & \multicolumn{3}{|c|}{ Any DV Recidivism } & \multicolumn{3}{|c|}{$\underline{\text { Violent DV Recidivism }}$} \\
\hline & B & SE & $\operatorname{Exp}(B)$ & B & SE & $\operatorname{Exp}(B)$ \\
\hline Lethal Threats (Victim/Kids) & .01 & .20 & 1.01 & .08 & .20 & 1.08 \\
\hline Assaulted Pregnant Victim & .22 & .23 & 1.25 & .00 & .24 & 1.00 \\
\hline Escalating Violence & .11 & .15 & 1.12 & .03 & .15 & 1.03 \\
\hline Recent Separation & .19 & .14 & 1.21 & .17 & .15 & 1.18 \\
\hline Controlling Behavior & -.24 & .18 & .79 & -.30 & .19 & .74 \\
\hline Stalking Behavior & .22 & .18 & 1.25 & .29 & .19 & 1.34 \\
\hline Constant & $-.68 * * *$ & .10 & & $-.88^{* * *}$ & .10 & \\
\hline -2 Log Likelihood & & $1,344.49$ & & & $1,265.96$ & \\
\hline Chi-Squared & & 7.42 & & & 6.22 & \\
\hline Nagelkerke R Squared & & .01 & & & .08 & \\
\hline$A \cup C$ & & .55 & & & .55 & \\
\hline
\end{tabular}


RQ 6 - Current Offense Characteristics

Our sixth set of analyses examined research question number six, regarding the predictive value of the current incident characteristics. This set of variables whether the incident was a violent offense, whether a weapon was used, if a protective order was violated, and if officers had to use force. I also included victim information including if any children witnessed the event, if any lethal threats were made, if the victim was choked, the victim injury and pain level, if medical treatment was provided to the victim, and if alcohol or drugs were used by the suspect during the incident.

A number of previous studies have found a positive effect from the placement of a protective order. Some studies have found a decrease in physical violence (Carson et al., 1999), a decrease in the use of threats and weapons (Holt et al., 2003), and a decrease in injury to the victim (Holt et al., 2003; Spencer et al., 2019). This next analysis seeks to determine if the use of violence, weapons, protective order violations, or use of force by officers in the current incident increases the risk of DV recidivism. In the current sample, a violent offense was committed by 83.2 percent of the suspects (see Table 11). Committing a violent offense during the index incident decreases the risk of any new DV recidivism and any new violent DV recidivism, but these correlations were not significant $(p<.05)$. Weapons were used by 8.3 percent, but the negative correlations to DV recidivism and violent DV recidivism was not significant $(p<.05)$. The violation of a protective order $(2.2 \%)$ was positively correlated with DV recidivism and violent DV recidivism, but the correlations were not significant 
$(p<.05)$. Similarly, the use of force by officers during the incident $(1.1 \%)$ was found to be positively correlated to DV recidivism and violent DV recidivism, but was not statistically significant $(p<.05)$. None of the variables had a statistically significant impact on the multivariate logistic regression model (see Table 12).

As stated previously, a recent study by Spencer et al. (2019) found the presence of children and victim injury to be predictors of IPV. This analysis aims to determine if the presence of children and the injury to the victim is correlated with DV recidivism. In 60.3 percent of the sample, children witnessed the index incident (see Table 11). Children witnessing the incident was negatively correlated with DV recidivism, but positively correlated with violent DV recidivism. These correlations were not significant $(p<.05)$. The use of lethal threats $(23.6 \%)$ was positively associated with DV recidivism and violent DV recidivism, but neither correlation was significant $(p<.05)$. Victims indicated they were choked by the suspect in 14.2 percent of the sample, and although it was positively associated with DV recidivism and violent DV recidivism, these correlations were not significant $(p<.05)$. Victim injury was reported in 54.1 percent of the sample averaging 2.68(3.15) and ranging from 1 to 10. Victim injury/pain level was negatively associated with DV recidivism and violent DV recidivism, but these correlations were not significant $(p<.05)$. Medical treatment was indicated in 10.6 percent of the sample. Medical treatment provided to the victim was positively associated with violent DV recidivism $(r=.06, p<.05)$. The positive association with DV recidivism was not statistically significant $(p<.05)$. Shown in Table 12, victim injury and pain level made a statistically significant impact in the multivariate logistic regression model. 
Several studies in IPV literature have found an association between substance use and domestic offending (Devries et al., 2013; Spencer et al., 2019). This next analysis will determine if recent alcohol or drug use during the current offense is correlated with DV recidivism. Shown in Table 11, recent alcohol use was reported in 53.3 percent of the sample but was not correlated with DV recidivism or violent DV recidivism. Recent drug use was reported in 7.2 percent of the sample and was found to be positively correlated with DV recidivism $(r=.02, p<.05)$ and violent DV recidivism $(r=.06, p<.05)$. Similarly, recent drug use made a significant impact in the multivariate logistic regression model, while recent alcohol use did not make an impact (see Table 12).

The combination of current offense characteristics led to a statistically significant model for predicting DV recidivism but not for violent DV recidivism. The model produced an AUC of .61 for DV recidivism and .66 for violent DV recidivism suggesting a medium effect (see Table 12). The AUC score suggests the current offense characteristics are only moderately able to predict violent DV recidivism. 
Table 11.

Descriptive Statistics for Current Offense Characteristics and Bivariate Correlation with DV Recidivism.

\begin{tabular}{|c|c|c|c|c|}
\hline Factors (data source) & $\mathrm{n}$ & $\%$ or $\mathrm{M}(\mathrm{SD})$ & $\begin{array}{c}\text { Any DV } \\
\text { Recidivism } \\
\text { (r) }\end{array}$ & $\begin{array}{c}\text { Violent DV } \\
\text { Recidivism } \\
\text { (r) }\end{array}$ \\
\hline \multicolumn{5}{|l|}{ Violent Offense (Incident Rpt.) } \\
\hline$Y_{e s}{ }^{a}$ & 1,594 & $83.2 \%$ & -.02 & -.01 \\
\hline No & 321 & $16.8 \%$ & & \\
\hline \multicolumn{5}{|l|}{ Weapon Used (Incident Rpt.) } \\
\hline Yes $^{a}$ & 159 & $8.3 \%$ & -.04 & -.03 \\
\hline No & 1,756 & $91.7 \%$ & & \\
\hline \multicolumn{5}{|l|}{ Violation P.O. (Incident Rpt.) } \\
\hline Yes $^{a}$ & 43 & $2.2 \%$ & .04 & .04 \\
\hline No & 1,872 & $97.8 \%$ & & \\
\hline \multicolumn{5}{|l|}{ Officer(s) Used Force (Incident Rpt.) } \\
\hline Yes $^{a}$ & 22 & $1.1 \%$ & .02 & .02 \\
\hline No & 1,893 & $98.9 \%$ & & \\
\hline \multicolumn{5}{|l|}{ Child(ren) Witnessed (Fam Suppl.) } \\
\hline$Y_{e s}{ }^{a}$ & 222 & $60.3 \%$ & -.02 & .02 \\
\hline No & 146 & $39.7 \%$ & & \\
\hline \multicolumn{5}{|l|}{ Lethal Threats (Fam Suppl.) } \\
\hline Yes $^{\mathrm{a}}$ & 431 & $23.6 \%$ & .01 & .04 \\
\hline No & 1,395 & $76.4 \%$ & & \\
\hline \multicolumn{5}{|l|}{ Victim Choked (Fam Suppl.) } \\
\hline Yes $^{a}$ & 261 & $14.2 \%$ & .03 & .04 \\
\hline No & 1,582 & $85.8 \%$ & & \\
\hline Victim Injury/Pain Level (Fam Suppl.) & 1,747 & $2.68(3.15)$ & .01 & -.00 \\
\hline Any Victim Injury/Pain ${ }^{a}$ & 945 & $54.1 \%$ & -.03 & -.05 \\
\hline \multicolumn{5}{|l|}{ Medical Treatment (Fam Suppl.) } \\
\hline Yes $^{a}$ & 151 & $10.6 \%$ & .05 & $.06 *$ \\
\hline No & 1,272 & $89.4 \%$ & & \\
\hline \multicolumn{5}{|l|}{ Recent Alcohol Use (Fam Suppl.) } \\
\hline Yes $^{\mathrm{a}}$ & 933 & $53.3 \%$ & .00 & .00 \\
\hline No & 818 & $46.7 \%$ & & \\
\hline \multicolumn{5}{|l|}{ Recent Drug Use (Fam Suppl.) } \\
\hline$Y_{e s}^{a}$ & 126 & $7.2 \%$ & $.02 *$ & $.06 *$ \\
\hline No & 1,625 & $92.8 \%$ & & \\
\hline
\end{tabular}

$* p<.05, * * p<.01, * * * p<.001$.

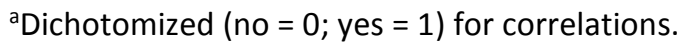


Table 12.

Logistic Regression Predicting DV Recidivism Using Current Offense Characteristics.

\begin{tabular}{|c|c|c|c|c|c|c|}
\hline & \multicolumn{3}{|c|}{ Any DV Recidivism } & \multicolumn{3}{|c|}{$\underline{\text { Violent DV Recidivism }}$} \\
\hline & B & SE & $\operatorname{Exp}(B)$ & B & SE & $\operatorname{Exp}(B)$ \\
\hline Violent Offense & -.01 & .36 & .98 & -.02 & .38 & .98 \\
\hline Weapon Used & -.30 & .54 & .74 & -.27 & .58 & .76 \\
\hline Violation P.O. & 1.02 & .80 & 2.76 & 1.27 & .81 & 3.55 \\
\hline Officer(s) Used Force & 1.54 & 1.18 & 4.68 & 1.82 & 1.18 & 6.15 \\
\hline Child(ren) Witnessed & -.11 & .27 & 1.12 & .33 & .29 & 1.39 \\
\hline Lethal Threats & .43 & .28 & 1.54 & .52 & .30 & 1.68 \\
\hline Victim Choked & .17 & .36 & 1.19 & .21 & .39 & 1.23 \\
\hline Victim Injury/Pain Level & $-.09 *$ & .05 & .91 & $-.14^{*}$ & .05 & .87 \\
\hline Medical Treatment & .71 & .50 & 2.03 & 1.03 & .53 & 2.81 \\
\hline Recent Alcohol Use & .08 & .26 & 1.08 & .09 & .28 & 1.10 \\
\hline Recent Drug Use & $1.13^{*}$ & .50 & 3.10 & $1.02 *$ & .51 & 2.76 \\
\hline Constant & $-.87 *$ & .40 & & $-1.25^{* *}$ & .43 & \\
\hline -2 Log Likelihood & & 361.60 & & & 329.01 & \\
\hline Chi-Squared & & 18.10 & & & $24.21^{* *}$ & \\
\hline Nagelkerke R Squared & & .08 & & & .11 & \\
\hline AUC & & .61 & & & .66 & \\
\hline
\end{tabular}

${ }^{*} p<.05,{ }^{* *} p<.01,{ }^{* * *} p<.001$. 


\section{RQ 7 - Victim-Rated Risk}

Our seventh analyses examined research question seven, regarding the predictive value of victim-rated risk for DV recidivism. This set of variables includes the victimrated risk score, any risk indicated by the victim, and whether the victim indicated high or low risk.

Multiple studies have found strong predictive accuracy with victim-rated risk (Campbell et al., 2009; Messing and Thaller, 2013; Weisz et al., 2000; Goodman et al., 2000). This analysis aims to assess the association between victim-rated risk and DV recidivism. Shown in Table 13, 75.9 percent of victims indicated some risk, and 47.2 percent indicated high risk, averaging a score of 5.47(3.47). Shown in Table 13, victimrated risk was positively associated with DV recidivism $(r=.14, p<.001)$ and violent DV recidivism $(r=.13, p<.001)$.

In the multivariate logistic regression model, the continuous variable for victimrated risk was used. An AUC of .58 was generated for both DV recidivism and violent DV recidivism suggesting the model does slightly better than chance for predicting DV recidivism. Although our model was statistically significant $(p<.05)$, our AUC scores suggest a small effect. Victim-rated risk is a weak predictor for DV recidivism and violent DV recidivism. 
Table 13.

Descriptive Statistics for Victim-Rated Risk and Bivariate Correlation with DV Recidivism.

\begin{tabular}{|c|c|c|c|c|}
\hline Factors (data source) & $n$ & $\%$ or $\mathrm{M}(\mathrm{SD})$ & $\begin{array}{c}\text { Any DV } \\
\text { Recidivism } \\
\text { (r) }\end{array}$ & $\begin{array}{c}\text { Violent DV } \\
\text { Recidivism } \\
\text { (r) }\end{array}$ \\
\hline Victim-Rated Risk 1-10 (Victim Int.) & 1,172 & $5.47(3.47)$ & $.14^{* * *}$ & $.13^{* * *}$ \\
\hline Any Risk (1 vs $2-10)^{b}$ & 890 & $75.9 \%$ & $.12 * * *$ & $.12 * * *$ \\
\hline High Risk (1-5 vs 6-10) b & 553 & $47.2 \%$ & $.12 * * *$ & $.12 * * *$ \\
\hline
\end{tabular}


RQ 8a - In a previous study, they found combining risk factors from different tools yielded a high AUC (Van der put, 2019). I assessed whether combining risk factors from multiple sources increased the utility of the model. I combined the significant predictors from the incident report, RMS, and family supplemental form, shown in Table 14. I excluded the victim interview from the model and generated a statistically significant model $(p<.05)$ with an AUC of .74 for DV recidivism and violent DV recidivism. Our AUC scores suggest a large effect; the risk factors collected from these sources are good predictors of DV recidivism and violent DV recidivism.

$$
\text { RQ } 8 b \text { - The next analysis assessed the predictive strength when the }
$$

significant variables from the victim interview (excluding victim-rated risk) were added to the model. I generated an AUC of .74 for DV recidivism and violent DV recidivism $(p<.05)$ (see Table 15). Adding the risk factors from the victim interview to the existing predictive model did not significantly improve the overall AUC for either DV recidivism $(\mathrm{Z}=.142, p=n s$.$) or violent \mathrm{DV}$ recidivism $(\mathrm{Z}=.516, p=n s$.$) .$

RQ 8c - Next, I analyzed the significant variables from the incident report, RMS, family supplemental, and included victim-rated risk. This model was statistically significant $(p<.05)$ and generated an AUC of .73 for DV recidivism and .74 for violent DV recidivism (see Table 16). Similarly, this model did not generate a high enough zscore to determine if this model is a significant improvement for predicting $\mathrm{DV}(\mathrm{Z}=$ $1.420, p=n s$.$) recidivism and violent \mathrm{DV}$ recidivism $(\mathrm{Z}=.000, p=n s$.$) from the$ previous model. 
RQ 8d - Our final model consisted of all the significant variables from the incident report, RMS, family supplemental, and victim interview including victim-rated risk. Shown in Table 17, our model was statistically significant $(p<.05)$ and generated an AUC of .73 for DV recidivism and .74 for violent DV recidivism. When comparing the dependent AUC's, I found that model 1 containing risk factors from the incident report, RMS and family supplemental was a statistically significant improvement from model 4 containing all significant risk factors $(Z=2.12)$.

Overall, the model containing significant variables from the incident report, RMS, and family supplemental generated the highest AUC and the best predictive utility for DV recidivism and violent DV recidivism. I did not see any significant improvements when variables from the victim interview were added to the model. Similarly, I did not see any significant improvements when victim-rated risk was added to the model. 
Table 14.

Logistic Regression Predicting DV Recidivism Using Information from the Incident Report, RMS and Family Supplemental

\begin{tabular}{|c|c|c|c|c|c|c|}
\hline \multirow[b]{2}{*}{ Factors } & \multicolumn{3}{|c|}{ Any DV Recidivism } & \multicolumn{3}{|c|}{ Violent DV Recidivism } \\
\hline & $\mathrm{B}$ & SE & $\operatorname{Exp}(B)$ & B & SE & $\operatorname{Exp}(B)$ \\
\hline \multicolumn{7}{|l|}{ Incident Rpt. } \\
\hline Race - Black ${ }^{a}$ & .13 & .16 & 1.14 & .10 & .16 & 1.10 \\
\hline Male $^{b}$ & .15 & .18 & 1.17 & .14 & .19 & 1.15 \\
\hline \multicolumn{7}{|l|}{ RMS } \\
\hline \# Prior Alcohol/Drug & -.04 & .03 & .96 & -.03 & .03 & .97 \\
\hline Flagged Suicidal & .19 & .33 & 1.21 & .24 & .33 & 1.27 \\
\hline Age of $1^{\text {st }}$ Suspect & $-.02 * *$ & .01 & .98 & $-.02 *$ & .01 & .98 \\
\hline \# Prior Arrests & $.02 *$ & .01 & 1.02 & .02 & .01 & 1.02 \\
\hline \# Prior Violent Offenses & -.02 & .03 & .98 & .00 & .03 & 1.00 \\
\hline \# Prior DV Reports & $.07^{* *}$ & .02 & 1.07 & $.05^{* *}$ & .02 & 1.05 \\
\hline \# Prior DV Last Year & $.35 * * *$ & .07 & 1.42 & $.34 * * *$ & .07 & 1.41 \\
\hline Elude/Resist Arrest Flag & .57 & .30 & 1.78 & $.66^{*}$ & .30 & 1.94 \\
\hline \multicolumn{7}{|l|}{ Fam Suppl. } \\
\hline Victim is Pregnant & .35 & .27 & 1.42 & .33 & .28 & 1.40 \\
\hline Married & -.22 & .19 & .80 & -.26 & .20 & .77 \\
\hline Currently Separated & -.09 & .17 & .91 & -.10 & .18 & .91 \\
\hline Victim Depend Transport & -.55 & .28 & .58 & $-.76^{*}$ & .31 & .47 \\
\hline Medical Treatment & .05 & .23 & 1.05 & .11 & .23 & 1.12 \\
\hline Recent Drug Use & .09 & .26 & 1.09 & .09 & .26 & 1.10 \\
\hline Constant & & $-.80 * *$ & .26 & $-1.03 * *$ & .26 & \\
\hline-2 Log Likelihood & \multicolumn{3}{|c|}{$1,294.61$} & \multicolumn{3}{|c|}{$1,229.18$} \\
\hline Chi-Squared & \multicolumn{3}{|c|}{$185.59 * * *$} & \multicolumn{3}{|c|}{$177.77 * * *$} \\
\hline Nagelkerke R Squared & \multicolumn{3}{|c|}{.21} & \multicolumn{3}{|c|}{.20} \\
\hline AUC & \multicolumn{3}{|c|}{.74} & \multicolumn{3}{|c|}{.74} \\
\hline
\end{tabular}

$* p<.05, * * p<.01, * * * p<.001$.

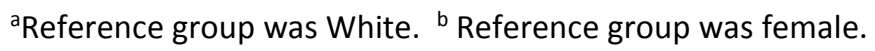


Table 15.

Logistic Regression Predicting DV Recidivism Using Information from the Incident Report, RMS, Family Supplemental and Victim Interview (Excluding Victim-Rated Risk)

\begin{tabular}{|c|c|c|c|c|c|c|}
\hline \multirow[b]{2}{*}{ Factors } & \multicolumn{3}{|c|}{$\underline{\text { Any DV Recidivism }}$} & \multicolumn{3}{|c|}{ Violent DVRecidivism } \\
\hline & B & SE & $\operatorname{Exp}(B)$ & B & SE & $\operatorname{Exp}(B)$ \\
\hline \multicolumn{7}{|l|}{ Incident Rpt. } \\
\hline Race - Black ${ }^{a}$ & .21 & .20 & 1.24 & .25 & .21 & 1.23 \\
\hline Male $^{b}$ & .00 & .21 & 1.00 & -.09 & .22 & .91 \\
\hline \multicolumn{7}{|l|}{ RMS } \\
\hline \# Prior Alcohol/Drug & -.05 & .03 & .96 & -.04 & .03 & .96 \\
\hline Flagged Suicidal & .18 & .41 & 1.19 & .17 & .40 & 1.18 \\
\hline Age of $1^{\text {st }}$ Arrest & -.02 & .01 & .99 & -.02 & .01 & .99 \\
\hline \# Prior Arrests & $.03^{*}$ & .01 & 1.03 & $.03^{*}$ & .01 & 1.03 \\
\hline \# Prior Violent Offenses & -.05 & .04 & .95 & -.03 & .03 & .97 \\
\hline \# Prior DV Reports & $.06^{*}$ & .02 & 1.06 & .04 & .02 & 1.04 \\
\hline \# Prior DV Last Year & $.36 * * *$ & .08 & 1.43 & $.35 * * *$ & .08 & 1.43 \\
\hline Elude/Resist Arrest Flag & $1.11^{* *}$ & .36 & 3.05 & $1.16^{* *}$ & .36 & 3.20 \\
\hline \multicolumn{7}{|l|}{ Fam Suppl. } \\
\hline Victim is Pregnant & .15 & .36 & 1.17 & .05 & .37 & 1.06 \\
\hline Married & -.39 & .22 & .68 & -.39 & .23 & .68 \\
\hline Currently Separated & -.20 & .22 & .82 & -.21 & .22 & .81 \\
\hline Victim Depend Transport & $-.70 *$ & .35 & .50 & $-.88 *$ & .39 & .41 \\
\hline Medical Treatment & -.06 & .29 & .94 & -.08 & .30 & .92 \\
\hline Recent Drug Use & .66 & .35 & 1.93 & .55 & .36 & 1.74 \\
\hline \multicolumn{7}{|l|}{ Victim Int. } \\
\hline History of Alcohol Problem & $.47^{*}$ & .18 & 1.60 & $.43^{*}$ & .18 & 1.54 \\
\hline History of Drug Problem & -.31 & .24 & .74 & -.34 & .25 & .71 \\
\hline Violent Outside Home & -.05 & .21 & .95 & .12 & .21 & 1.13 \\
\hline Constant & & $-.88 * *$ & .31 & $-1.05^{* *}$ & .33 & \\
\hline-2 Log Likelihood & & 890.96 & & & 837.94 & \\
\hline Chi-Squared & & $121.51^{* * *}$ & & & $115.01 * * *$ & \\
\hline Nagelkerke R Squared & & .20 & & & .19 & \\
\hline AUC & & .74 & & & .74 & \\
\hline
\end{tabular}

$* p<.05, * * p<.01, * * * p<.001$.

${ }^{\text {a }}$ Reference group was White. ${ }^{\mathrm{b}}$ Reference group was female. 
Table 16.

Logistic Regression Predicting DV Recidivism Using Information from the Incident Report, RMS, Family Supplemental and Victim-Rated Risk from the Victim Interview

\begin{tabular}{|c|c|c|c|c|c|c|}
\hline \multirow[b]{2}{*}{ Factors } & \multicolumn{3}{|c|}{ Any DV Recidivism } & \multicolumn{3}{|c|}{ Violent DV Recidivism } \\
\hline & B & SE & $\operatorname{Exp}(B)$ & B & SE & $\operatorname{Exp}(B)$ \\
\hline \multicolumn{7}{|l|}{ Incident Rpt. } \\
\hline Race - Black ${ }^{\mathrm{a}}$ & .17 & .19 & 1.18 & .16 & .20 & 1.17 \\
\hline Male $^{b}$ & .05 & .22 & 1.05 & -.02 & .23 & .98 \\
\hline \multicolumn{7}{|l|}{ RMS } \\
\hline \# Prior Alcohol/Drug & -.04 & .03 & .96 & -.04 & .03 & .96 \\
\hline Flagged Suicidal & -.12 & .42 & .89 & -.21 & .44 & .81 \\
\hline Age of $1^{\text {st }}$ Arrest & -.02 & .01 & .98 & -.02 & .01 & .98 \\
\hline \# Prior Arrests & .03 & .01 & 1.03 & .02 & .01 & 1.02 \\
\hline \# Prior Violent Offenses & -.04 & .03 & .97 & -.01 & .03 & .99 \\
\hline \# Prior DV Reports & $.06^{*}$ & .02 & 1.06 & .04 & .02 & 1.04 \\
\hline \# Prior DV Last Year & $.28 * * *$ & .08 & 1.32 & $.29 * * *$ & .08 & 1.34 \\
\hline Elude/Resist Arrest Flag & $.74^{*}$ & .35 & 2.09 & $.82^{*}$ & .34 & 2.27 \\
\hline \multicolumn{7}{|l|}{ Fam Suppl. } \\
\hline Victim is Pregnant & .37 & .35 & 1.45 & .21 & .36 & 1.23 \\
\hline Married & -.38 & .23 & .68 & -.38 & .24 & .69 \\
\hline Currently Separated & -.09 & .21 & .91 & -.14 & .22 & .87 \\
\hline Victim Depend Transport & $-.74 *$ & .35 & .48 & $-1.12 * *$ & .42 & .33 \\
\hline Medical Treatment & -.03 & .29 & .97 & -.04 & .30 & .97 \\
\hline Recent Drug Use & .39 & .31 & 1.48 & .29 & .32 & 1.33 \\
\hline \multicolumn{7}{|l|}{ Victim Int. } \\
\hline Victim-Rated Risk & .04 & .03 & 1.04 & .05 & .03 & 1.05 \\
\hline Constant & $-.91 * *$ & .33 & & $-1.16^{* *}$ & .35 & \\
\hline -2 Log Likelihood & & 883.27 & & & 824.06 & \\
\hline Chi-Squared & & $117.73 * * *$ & & & $117.38^{* * *}$ & \\
\hline Nagelkerke R Squared & & .20 & & & .20 & \\
\hline AUC & & .73 & & & .74 & \\
\hline
\end{tabular}


Table 17.

Logistic Regression Predicting DV Recidivism Using Information from the Incident Report, RMS, Family Supplemental, and Victim Interview (Including Victim-Rated Risk)

\begin{tabular}{|c|c|c|c|c|c|c|}
\hline \multirow[b]{2}{*}{ Factors } & \multicolumn{3}{|c|}{ Any DV Recidivism } & \multicolumn{3}{|c|}{$\underline{\text { Violent DV Recidivism }}$} \\
\hline & B & SE & $\operatorname{Exp}(B)$ & B & SE & $\operatorname{Exp}(B)$ \\
\hline \multicolumn{7}{|l|}{ Incident Rpt. } \\
\hline Race - Black ${ }^{\mathrm{a}}$ & .29 & .22 & 1.33 & .31 & .23 & 1.37 \\
\hline Male $^{b}$ & .05 & .24 & 1.05 & -.08 & .24 & .92 \\
\hline \multicolumn{7}{|l|}{ RMS } \\
\hline \# Prior Alcohol/Drug & -.05 & .04 & .95 & -.05 & .04 & .95 \\
\hline Flagged Suicidal & .08 & .46 & 1.08 & -.05 & .46 & .96 \\
\hline Age of $1^{\text {st }}$ Arrest & -.02 & .01 & .98 & -.02 & .01 & .98 \\
\hline \# Prior Arrests & .03 & .01 & 1.03 & $.03^{*}$ & .01 & 1.03 \\
\hline \# Prior Violent Offenses & -.06 & .04 & .95 & -.04 & .04 & .96 \\
\hline \# Prior DV Reports & $.05^{*}$ & .02 & 1.05 & .03 & .02 & 1.03 \\
\hline \# Prior DV Last Year & $.30 * *$ & .09 & 1.34 & $.32 * * *$ & .09 & 1.37 \\
\hline Elude/Resist Arrest Flag & $1.09 * *$ & .38 & 2.98 & $1.15^{* *}$ & .38 & 3.14 \\
\hline \multicolumn{7}{|l|}{ Fam Suppl. } \\
\hline Victim is Pregnant & .24 & .39 & 1.28 & .09 & .41 & 1.10 \\
\hline Married & $-.49 *$ & .24 & .62 & -.50 & .26 & .61 \\
\hline Currently Separated & -.21 & .23 & .81 & -.24 & .24 & .78 \\
\hline Victim Depend Transport & $-.86^{*}$ & .38 & .42 & $-.98^{*}$ & .43 & .38 \\
\hline Medical Treatment & .00 & .31 & 1.00 & -.06 & .33 & .94 \\
\hline Recent Drug Use & .72 & .38 & 2.06 & .58 & .39 & 1.78 \\
\hline \multicolumn{7}{|l|}{ Victim Int. } \\
\hline History of Alcohol Problem & $.46^{*}$ & .19 & 1.59 & $.44^{*}$ & .20 & 1.55 \\
\hline History of Drug Problem & -.32 & .25 & .73 & -.37 & .26 & .69 \\
\hline Violent Outside Home & -.11 & .22 & .90 & .07 & .23 & 1.08 \\
\hline Victim-Rated Risk Score & .03 & .03 & 1.03 & .03 & .03 & 1.03 \\
\hline Constant & & $-.92^{*}$ & .36 & -1.07 & .38 & \\
\hline-2 Log Likelihood & & 779.37 & & & 726.93 & \\
\hline Chi-Squared & & 106.21 & & & $102.54 * *$ & \\
\hline Nagelkerke R Squared & & .20 & & & .20 & \\
\hline AUC & & .73 & & & .74 & \\
\hline
\end{tabular}

$* p<.05, * * p<.01, * * * p<.001$.

${ }^{a}$ Reference group was White. ${ }^{b}$ Reference group was female. 


\section{Chapter 5}

\section{Discussion}

Several studies have found that IPV causes negative consequences in adults and children, ranging from mental health deficits (Wolfe et al., 2003; Kitzmann et al., 2003) to fatality (Petrosky et al., 2017). IPV may cause a cycle of violence when violent behavior is observed by a child and then imitated in that child's future relationships (Stith et al., 2000). Due to the negative impact and high prevalence of IPV, the criminal justice system had implemented preventative strategies to reduce IPV (Bowen, 2011). We see these strategies manifest in mandatory arrest laws for domestic violence offenders and the use of risk assessment instruments by law enforcement to prioritize cases. Risk assessment instruments use empirically tested risk factors to determine if an offender is at risk for re-offending with the purpose of implementing supervision and treatment to reduce the rate of IPV (Hanson, 2009).

This study assessed whether the information available from police records and criminal incident reports could be used to predict DV recidivism and violent DV recidivism. I used risk factors from the incident report, records management system (RMS), Family Abuse Supplemental Form, and victim interview used by a mid-sized western city. I grouped the risk factors into domains including demographic information, suspect mental health history, suspect criminal history, suspect-victim relationship characteristics, suspect-victim IPV history, current offense characteristics, and victim rated risk. I also aim to assess the added predictive value of including the victim interview risk factors and victim-rated risk. 
Starting with demographic factors, I first analyzed the utility of the suspect's age, race, and sex for predicting DV recidivism and violent DV recidivism. Although age was negatively associated with recidivism, I did not generate significant correlations with recidivism. Relative to other racial/ethnic groups, Black suspects were more likely to recidivate for DV recidivism and violent DV recidivism. This positive correlation was similar to the results found in previous literature (Cattaneo and Goodman, 2005). Despite the fact that prior research has suggested that female suspects would exhibit a higher prevalence of aggression in our sample compared to males, that wasn't the case in this study. Compared to females, male suspects were more likely to recidivate for DV and violent DV.

When other risk factors were entered into the regression model, race and gender dropped out as predictors. A potential explanation for race being correlated with recidivism may be attributed to minority populations being policed at higher rates than non-minority populations. Using race and gender as predictors for recidivism has been rooted in controversy due to the racial disparity within policing practices. These disparities also reflect in risk assessment instruments where commonly used risk factors such as criminal history, unemployment, and substance abuse may be a "proxy" for race due to cumulative disadvantage (Skeen and Lowencamp, 2016). Future research may benefit from implementing a race-neutral risk scale and consider the risk factors that may be attributed to cumulative disadvantage rather than risk of recidivism.

Despite prior research suggesting good predictive utility from demographic information, I found very little value for predicting DV recidivism. From our model, I 
can suggest that demographic information indeed predicts recidivism, but the effect is small (Rice and Harris, 2005).

The next analysis assessed the predictive value of the suspect's mental health history for DV recidivism and violent DV recidivism. Similar to several previous research studies, I found that having prior alcohol/drug offenses or a history of alcohol or drug problems each increased the risk for recidivism. Suspects are often flagged in the RMS if previous suicidal behavior has been detected. I found previously indicated suicidal behavior increased the risk for DV recidivism and violent DV recidivism. These findings support the second hypothesis by suggesting that I can predict recidivism using aspects of the suspect's mental health history. Although the suspect's mental health history was a better predictor for recidivism than demographic information, I still found limited value.

Corresponding with several studies, a suspect's age being first listed as a suspect was negatively associated with DV recidivism and violent DV recidivism. This suggests that as the suspect's age being first listed as a suspect in the RMS increases, the risk of recidivism decreases. An interesting finding in this analysis was numerous suspects being first listed as a suspect during early childhood. Also corresponding to previous literature, I found the risk of recidivism increases if the suspect has prior arrests, prior violent offenses, prior DV reports, or prior DV reports in the last year. Being flagged in the RMS for DV was positively associated with recidivism but was not significant. This may be due to the small sample size of suspects being flagged for DV. Eluding or resisting arrest increased the likelihood of DV recidivism and violent DV recidivism. Similarly, the suspects who are violent outside the home are more likely to recidivate than those who 
are not. Criminal history was the strongest predictor of DV recidivism and violent DV recidivism offering the greatest predictive utility. This study found support for the third hypothesis with criminal history being positively associated with DV recidivism.

The fourth research question assessed whether suspect-victim relationship characteristics were positively correlated with DV recidivism. While the number of children and shared children did not generate significant results, I did find a positive association between violence while the victim is pregnant and DV recidivism. When I analyzed the relationship status, I found that marriage was negatively associated with recidivism and the opposite effect for currently separated couples, corresponding with several prior research studies. I may be generating this finding due to marriage being a protective factor against partner violence or underreporting of abuse among married couples. Victim vulnerability factors, such as being reliant on the suspect for transportation was negatively associated with recidivism. This was an unexpected finding because several studies have found the opposite effect. I may be seeing this finding as a result of measurement error. Our multivariate logistic regression model suggests that suspect-victim relationship characteristics are predictors of DV recidivism and violent DV recidivism. Using the interpretation of effect sizes for AUCs determined by Rice and Harris (2005), I can suggest that our AUCs for suspect-victim relationship characteristics are small and, therefore, weak predictors for DV recidivism. I found partial support for our hypothesis with victim pregnancy and current separation being positively correlated with DV recidivism.

I assessed the predictive value of suspect-victim IPV history in the fifth research question. None of the risk factors in this section were statistically significant $(p<.05)$. 
An interesting finding was the negative correlation between a suspect's controlling behavior and violent DV recidivism. This may have been due to an error in measurement with the information not being recorded in the supplemental form. Despite the fact that previous literature has suggested otherwise, I reject our fifth hypothesis due to a lack of support for suspect-victim IPV history being positively correlated with DV recidivism.

The sixth research question examined the utility of the current incident characteristics for predicting recidivism. Medical treatment provided to the victim and recent drug use was the only significant positive association with recidivism. An interesting finding was a negative association between victim injury/pain and recidivism. Although this finding was not statistically significant, it suggests that the risk of recidivism decreases when the victim is injured, contrary to previous literature. This may be another finding that is due to measurement error. Although many of the risk factors were not significant, the multivariate logistic regression model generated a medium effect size. I found partial support for our sixth hypothesis with medical treatment, and recent drug use being positively correlated with DV recidivism.

The association between victim-rated risk and DV recidivism was assessed in the seventh research question. Any risk and high risk indicated by the victim both increased the likelihood of DV recidivism and violent DV recidivism. I found support for the seventh hypothesis with victim-rated risk being positively correlated with DV recidivism. I used the continuous measure for victim-rated risk in the multivariate logistic regression. Although I found support for victim-rated risk being able to predict recidivism, the AUC for DV recidivism and violent DV recidivism suggests that it is a small/weak predictor. 
This finding did not align with previous literature and may be another case compromised by measurement error.

Overall, I found that the highest predictive strength came from combining the significant risk factors from the incident report, RMS, and family supplemental. I did not see an increase in predictive strength when the risk factors from the victim interview were added to the model. I witnessed a slight decrease in the AUC for DV recidivism when I included victim-rated risk with the risk factors from the incident report, RMS, and family supplemental. Similarly, I witnessed a slight decrease when all of the significant risk factors were included in the model. This finding may be due to a decrease in cases when risk factors from the victim interview and victim-rated risk were added to the model. Despite previous literature suggesting otherwise, I found very little utility from incorporating the risk factors from the victim interview and victim-rated risk to the model. From these findings, I must reject the hypothesis due to a lack of support for the increase in predictive utility when victim-rated risk was included in the model. The continuous victim-rated risk score was still correlated with recidivism, but dropped out of the multivariate logistic regression when other factors were included in the model. When the suspect's criminal history is unavailable, the victim-rated risk may still have value for predicting recidivism.

\section{Limitations}

While this study adds to the general research on IPV, it comes with limitations. A major limitation of this study is the potential for measurement error. A potential source of error is the victim failing to provide accurate information in the supplemental form. This could be intentional or unintentional on the victims' part. 
Another potential source of error is in the documentation by the officers. The officers recording the information may have failed to record all information disclosed by the victim or through filling the form out based on their own assumptions of the situation. While it is difficult to know the extent of measurement error in this study, it would be beneficial to inform the responding officers of the value of this research. Informing the officers of the value of the information recorded in the supplemental may reduce future measurement error.

An area of concern is the lack of full or partial supplementals available in the dataset. Noted earlier, interns were instructed to pull every other or every fourth supplemental form. In future studies, it would be beneficial to include a full or partial supplemental form with each case. Many of the insignificant correlations in our models were from the supplemental form. Having access to every supplemental form may have generated significant correlations for analysis and furthered IPV research.

When analyzing the AUC's for each domain and the collective groups of risk factors, I may or may not be able to compare these scores to previous risk assessment instruments. It is unknown if other risk assessment instruments such as the ODARA, DVSI, SARA, and DA used an IPV-only sample or expanded their sample to include all DV incidents. Without this knowledge, these results cannot be compared to previous risk assessment instruments.

\section{Policy Implications}

While I was not able to find support for all of our hypotheses, this study adds to the existing general research on the predictive strength of risk factors collected by the criminal justice system and adds to the understanding of incorporating static and dynamic 
factors and their ability to predict DV recidivism. This study will add to the research concerning the predictive strength of demographic information, suspect mental health history, criminal history, suspect-victim relationship and IPV history, and the current index offense characteristics. There is limited research available on the additive value of incorporating victim-rated risk with the information that is available in the criminal justice records management system. This study fills part of the gap in the limited literature on incorporating victim-rated risk to predict suspect recidivism.

A potential implication of this study is the exclusion of risk factors collected by law enforcement agencies. The information in the Family Abuse Supplemental form is vast, but many of the variables recorded in the form did not correlate with DV recidivism and violent DV recidivism. While the information in the supplemental form may serve other purposes for victim services, potentially removing these variables may reduce the strain on law enforcement officers and draw more attention to the risk factors that were better able to predict recidivism. While I could argue for the exclusion of some risk factors from the family supplemental form, I am resistant to suggest the exclusion of victim vulnerability factors. I do not know if the cases of DV recidivism was perpetrated against the same victim, and therefore cannot know the value of having victim vulnerability factors in the family supplemental form. The use of victim vulnerability factors may potentially be used by victim service providers to reduce the risk of revictimization as opposed to focusing on the risk of re-offending by the suspect.

An important finding from this research is the overall utility of suspect criminal history to predict recidivism. Criminal history was the strongest predictor of DV recidivism with an AUC of .71, suggesting a large effect. An implication of this finding is 
the suggestion for law enforcement agencies to rely on suspect criminal history to determine the risk of re-offending. Similarly, characteristics from the current offense and victim interview did not yield a high predictive utility and, therefore, may be less useful for law enforcement agencies. It may be beneficial to implement other sources of information and additional risk factors when criminal history is not available in the RMS. In the context of missing information from the RMS, risk factors from the victim interview and victim-rated risk may potentially have more value in predicting recidivism.

\section{Conclusion}

Violence between current and former intimate partners affected millions of people in the United States, potentially causing short and long term consequences to all members involved. Police agencies rely on risk factors and risk assessment tools to be accurate and empirically tested in their efforts to reduce IPV. This study assessed the predictive strength of risk factors collected by the incident report, RMS, and family supplemental form to collected by law enforcement agencies. I aimed to assess the additive value of incorporating risk factors from the victim interview and victim-rated risk.

Overall, I did not find support from the analysis to suggest that including victimrated risk to the model increased the predictive utility for DV recidivism. I did not find support from our analysis to suggest that including risk factors from the victim interview increased the predictive value for DV recidivism. I found that the strongest predictors for DV recidivism came from the suspect's criminal history. When I combined criminal history from the RMS with risk factors from the incident report and family supplemental form, I generated a large effect for predicting DV recidivism. The findings add support to the previous research suggesting an increase in predictive utility when combining 
multiple risk assessment tools. Future research may benefit from increasing the sample of supplemental forms in the analysis and reducing measurement error outlined in our limitations. 


\section{References}

Andrews, D.A., \& Bonta, J. (1998). The psychology of criminal conduct ( $2^{\text {nd }}$ ed.) Cincinnati, OH: Anderson Publishing Co.

Andrews, D. (1990). Recidivism is predictable and can be influenced: Using risk assessment to reduce recidivism. International Association of Residential and Community Alternatives, 3(1), 13-17.

Andrews, D. A., \& Dowden, C. (2006). Risk principle of case classification in correctional treatment: A meta-analytic investigation. International journal of offender therapy and comparative criminology, 50(1), 88-100.

Archer, J. (2000). Sex differences in aggression between heterosexual partners: A metaanalytic review. Psychological Bulletin, 126(5), 651-680.

Bendlin, M., \& Sheridan, L. (2019). Risk factors for severe violence in intimate partner stalking situations: an analysis of police records. Journal of interpersonal violence, 0886260519847776.

Bonta, J. (1996). Risk-needs assessment and treatment.

Bowen, E. (2011). An overview of partner violence risk assessment and the potential role of female victim risk appraisals. Aggression and Violent Behavior, 16(3), 214226.

Braga, A. A., \& Weisburd, D. L. (2012). The effects of "pulling levers" focused 
deterrence strategies on crime. Campbell systematic reviews, 8(1), 1-90.

Campbell, J., Webster, D., Koziol-McLain, J., \& Block, C. (2003). Risk factors for femicide in abusive relationships: Results from a multisite case control study. American Journal of Public Health, 93(7), 1089-97.

Campbell, J., Webster, D., \& Glass, N. (2009). The Danger Assessment: Validation of a lethality risk assessment instrument for intimate partner femicide. Journal of Interpersonal Violence, 24(4), 653-674.

Capaldi, D. M., Kim, H. K., \& Pears, K. C. (2009). The association between partner violence and child maltreatment: A common conceptual framework.

Capaldi, D. M., Knoble, N. B., Shortt, J. W., \& Kim, H. K. (2012). A systematic review of risk factors for intimate partner violence. Partner abuse, 3(2), 231-280.

Carlson, M. J., Harris, S. D., \& Holden, G. W. (1999). Protective orders and domestic violence: Risk factors for re-abuse. Journal of Family Violence, 14(2), 205-226.

Cattaneo, L. B., \& Goodman, L. A. (2005). Risk factors for reabuse in intimate partner violence: A cross-disciplinary critical review. Trauma, Violence, \& Abuse, 6(2), 141-175.

Churcher, F. P., \& Nesca, M. (2013). Risk factors for violence in stalking perpetration: A meta-analysis. FWU Journal of Social Sciences, 7(2), 100.

Coker, A. L., Smith, P. H., Bethea, L., King, M. R., \& McKeown, R. E. (2000). Physical 
health consequences of physical and psychological intimate partner violence. Archives of family medicine, 9(5), 451.

Cordier, R., Chung, D., Wilkes-Gillan, S., \& Speyer, R. (2019). The effectiveness of protection orders in reducing recidivism in domestic violence: a systematic review and meta-analysis. Trauma, Violence, \& Abuse, 1524838019882361.

Costa, B., Kaestle, C., Walker, A., Curtis, A., Day, A., Toumbourou, J., \& Miller, P. (2015). Longitudinal predictors of domestic violence perpetration and victimization: A systematic review. Aggression and Violent Behavior, 24, 261272.

Cui, M., Durtschi, J. A., Donnellan, M. B., Lorenz, F. O., \& Conger, R. D. (2010). Intergenerational transmission of relationship aggression: a prospective longitudinal study. Journal of Family Psychology, 24(6), 688.

Devries, K. M., Mak, J. Y., Bacchus, L. J., Child, J. C., Falder, G., Petzold, M., ... \& Watts, C. H. (2013). Intimate partner violence and incident depressive symptoms and suicide attempts: a systematic review of longitudinal studies. PLoS medicine, 10(5).

Dutton, M. A., \& Goodman, L. A. (2005). Coercion in intimate partner violence: Toward a new conceptualization. Sex roles, 52(11-12), 743-756.

Duwe, G., \& Rocque, M. (2017). Effects of automating recidivism risk assessment on 
reliability, predictive validity, and return on investment (ROI). Criminology \& Public Policy, 16(1), 235-269.

Flores, A. W., Lowenkamp, C. T., Smith, P., \& Latessa, E. J. (2006). Validating the Level of Service Inventory-Revised on a sample of federal probationers. Fed. Probation, 70, 44.

Gendreau, P., Little, T., \& Goggin, C. (1996). A meta $\square$ analysis of the predictors of adult offender recidivism: What works!. Criminology, 34(4), 575-608.

Golding, J. M. (1999). Intimate partner violence as a risk factor for mental disorders: A meta-analysis. Journal of family violence, 14(2), 99-132.

Goodman, L., Dutton, M., \& Bennett, L. (2000). Predicting Repeat Abuse Among Arrested Batterers: Use of the Danger Assessment scale in the criminal justice system. Journal of Interpersonal Violence, 15(1), 63-74.

Grove, W. M., Zald, D. H., Lebow, B. S., Snitz, B. E., \& Nelson, C. (2000). Clinical versus mechanical prediction: a meta-analysis. Psychological assessment, 12(1), 19.

Farrington, D. P. (2003). Methodological quality standards for evaluation research. The Annals of the American Academy of Political and Social Science, 587(1), 49-68.

Hanley, J., \& Mcneil, B. (1983). A method of comparing the areas under receiver operating characteristic curves derived from the same cases. Radiology, 148(3), 
839-843.

Hanson, R. K., \& Wallace-Capretta, S. (2004). Predictors of criminal recidivism among male batterers. Psychology, Crime \& Law, 10(4), 413-427.

Hanson, R. K., \& Morton-Bourgon, K. E. (2009). The accuracy of recidivism risk assessments for sexual offenders: a meta-analysis of 118 prediction studies. Psychological assessment, 21(1), 1.

Heckert, D. A., \& Gondolf, E. W. (2004). Battered women's perceptions of risk versus risk factors and instruments in predicting repeat reassault. Journal of interpersonal violence, 19(7), 778-800.

Hilton, N., Harris, G., Rice, M., Lang, C., Cormier, C., \& Lines, K. (2004). A Brief Actuarial Assessment for the Prediction of Wife Assault Recidivism: The Ontario Domestic Assault Risk Assessment. Psychological Assessment, 16(3), 267-275.

Hilton, N., Harris, G., Popham, S., \& Lang, C. (2010). Risk assessment among incarcerated male domestic violence offenders. Criminal Justice and Behavior, $37(8), 815-832$.

Hirschel, D., Buzawa, E., Pattavina, A., \& Faggiani, D. (2007). Domestic violence and mandatory arrest laws: To what extent do they influence police arrest decisions. J. Crim. L. \& Criminology, 98, 255.

Holt, S., Buckley, H., \& Whelan, S. (2008). The impact of exposure to domestic violence 89 
on children and young people: A review of the literature. Child abuse \& neglect, 32(8), 797-810.

Holtzworth-Munroe, A., \& Stuart, G. (1994). Typologies of male batterers: Three subtypes and the differences among them. Psychological Bulletin, 116(3), 476497.

Huang, C. C., Wang, L. R., \& Warrener, C. (2010). Effects of domestic violence on behavior problems of preschool-aged children: Do maternal mental health and parenting mediate the effects?. Children and Youth Services Review, 32(10), $1317-1323$.

Huang, C. C., Son, E., \& Wang, L. R. (2010). Prevalence and factors of domestic violence among unmarried mothers with a young child. Families in Society, 91(2), 171-177.

Hyman, I., Forte, T., Mont, J. D., Romans, S., \& Cohen, M. M. (2006). Help-seeking rates for intimate partner violence (IPV) among Canadian immigrant women. Health care for women international, 27(8), 682-694.

Johnson, M. P. (2011). Gender and types of intimate partner violence: A response to an anti-feminist literature review. Aggression and violent behavior, 16(4), 289-296.

Jung, S., \& Buro, K. (2017). Appraising Risk for Intimate Partner Violence in a Police Context. Criminal Justice and Behavior, 44(2), 240-260. 
Kerr, D. C., \& Capaldi, D. M. (2011). Young men's intimate partner violence and relationship functioning: long-term outcomes associated with suicide attempt and aggression in adolescence. Psychological medicine, 41(4), 759-769.

Kindness, A., Kim, H., Alder, S., Edwards, A., Parekh, A., \& Olson, L. (2009). Court compliance as a predictor of post adjudication recidivism for domestic violence offenders. Journal of Interpersonal Violence, 24(7), 1222-1238.

Kitzmann, K. M., Gaylord, N. K., Holt, A. R., \& Kenny, E. D. (2003). Child witnesses to domestic violence: a meta-analytic review. Journal of consulting and clinical psychology, 71(2), 339.

Kropp, P. R., \& Hart, S. D. (2004). The development of the Brief Spousal Assault Form for the Evaluation of Risk (B-SAFER): A tool for criminal justice professionals Research and Statistics Division, Department of Justice.

McEwan, T. E., Shea, D. E., Nazarewicz, J., \& Senkans, S. (2017). Reassessing the link between stalking and intimate partner abuse. Partner Abuse, 8(3), 223250.

Lipsky, S., Caetano, R., Field, C. A., \& Larkin, G. L. (2005). Psychosocial and substance-use risk factors for intimate partner violence. Drug and alcohol dependence, 78(1), 39-47.

Maxwell, C., Garner, J., \& Fagan, J. (2002). The Preventative Effects of Arrest on 
Intimate Partner Violence: Research, policy and theory. Criminology \& Public Policy, 2(1), 51-80.

McFarlane, J., Malecha, A., Gist, J., Watson, K., Batten, E., Hall, I., \& Smith, S. (2004). Increasing the Safety-Promoting Behaviors of Abused Women: In this study, a telephone intervention for victims of intimate-partner violence showed efficacy for 18 months. AJN The American Journal of Nursing, 104(3), 40-50.

Mallory, A. B., Dharnidharka, P., Deitz, S. L., Barros-Gomes, P., Cafferky, B., Stith, S. M., \& Van, K. (2016). A meta-analysis of cross cultural risk markers for intimate partner violence. Aggression and violent behavior, 31, 116-126.

Messing, J., \& Thaller, J. (2013). The average predictive validity of intimate partner violence risk assessment instruments. Journal of Interpersonal Violence, 28(7), $1537-1558$.

Messing, J., \& Campbell, J. (2016). Informing Collaborative Interventions: Intimate partner violence risk assessment for front line police officers. Policing: A Journal of Policy and Practice, 10(4), 328-340.

Morgan, K. D. (1994). Factors associated with probation outcome. Journal of Criminal Justice, 22(4), 341-353.

Murrell, A. R., Merwin, R. M., Christoff, K. A., \& Henning, K. R. (2005). When parents model violence: The relationship between witnessing weapon use as a child and 
later use as an adult. Behavior and Social Issues, 14(2), 128-134.

Murrell, A. R., Christoff, K. A., \& Henning, K. R. (2007). Characteristics of domestic violence offenders: Associations with childhood exposure to violence. Journal of family violence, 22(7), 523-532.

"NCADV: National Coalition Against Domestic Violence." The Nation's Leading Grassroots Voice on Domestic Violence, ncadv.org/statistics.

O'Donnell, C. J., Smith, A., \& Madison, J. R. (2002). Using demographic risk factors to explain variations in the incidence of violence against women. Journal of Interpersonal Violence, 17(12), 1239-1262.

Olson, D. E., \& Stalans, L. J. (2001). Violent offenders on probation: Profile, sentence, and outcome differences among domestic violence and other violent probationers. Violence against women, 7(10), 1164-1185.

Olver, M., \& Jung, S. (2017). Incremental prediction of intimate partner violence: An examination of three risk measures. Law and Human Behavior, 41(5), 440-453.

Petrosky, E., Blair, J. M., Betz, C. J., Fowler, K. A., Jack, S. P., \& Lyons, B. H. (2017). Racial and ethnic differences in homicides of adult women and the role of intimate partner violence-United States, 2003-2014. MMWR. Morbidity and mortality weekly report, 66(28), 741.

Rice, M. E., \& Harris, G. T. (2005). Comparing effect sizes in follow-up studies: ROC 93 
Area, Cohen's d, and r. Law and human behavior, 29(5), 615-620.

Rosenfeld, B. (2004). Violence risk factors in stalking and obsessional harassment: A review and preliminary meta-analysis. Criminal justice and behavior, 31(1), 9-36.

Sechrist, S. M., \& Weil, J. D. (2018). Assessing the impact of a focused deterrence strategy to combat intimate partner domestic violence. Violence against women, 24(3), 243-265.

Seedat, S., Stein, M. B., \& Forde, D. R. (2005). Association between physical partner violence, posttraumatic stress, childhood trauma, and suicide attempts in a community sample of women. Violence and victims, 20(1), 87-98.

Sherman, L. W., Smith, D. A., Schmidt, J. D., \& Rogan, D. P. (1992). Crime, punishment, and stake in conformity: Legal and informal control of domestic violence. American Sociological Review, 680-690.

Sims, B., \& Jones, M. (1997). Predicting success or failure on probation: Factors associated with felony probation outcomes. Crime \& Delinquency, 43(3), 314327.

Skeem, J. L., \& Lowenkamp, C. T. (2016). Risk, race, and recidivism: Predictive bias and disparate impact. Criminology, 54(4), 680-712.

Slashinski, M. J., Coker, A. L., \& Davis, K. E. (2003). Physical aggression, forced sex, and stalking victimization by a dating partner: An analysis of the National 
Violence Against Women Survey. Violence and Victims, 18(6), 595-617.

Smith, P. H., Thornton, G. E., DeVellis, R., Earp, J., \& Coker, A. L. (2002). A

population-based study of the prevalence and distinctiveness of battering, physical assault, and sexual assault in intimate relationships. Violence against women, $8(10), 1208-1232$.

Smith $\square$ Marek, E. N., Cafferky, B., Dharnidharka, P., Mallory, A. B., Dominguez, M., High, J., ... \& Mendez, M. (2015). Effects of childhood experiences of family violence on adult partner violence: A meta $\square$ analytic review. Journal of Family Theory \& Review, 7(4), 498-519.

Spencer, C. M., Stith, S. M., \& Cafferky, B. (2019). Risk markers for physical intimate partner violence victimization: A meta-analysis. Aggression and violent behavior, $44,8-17$.

Stith, S. M., Rosen, K. H., Middleton, K. A., Busch, A. L., Lundeberg, K., \& Carlton, R. P. (2000). The intergenerational transmission of spouse abuse: A meta $\square$ analysis. Journal of Marriage and Family, 62(3), 640-654.

Stith, S. M., Smith, D. B., Penn, C. E., Ward, D. B., \& Tritt, D. (2004). Intimate partner physical abuse perpetration and victimization risk factors: A meta-analytic review. Aggression and violent behavior, 10(1), 65-98.

Trevillion, K., Oram, S., Feder, G., \& Howard, L. M. (2012). Experiences of domestic 95 
violence and mental disorders: a systematic review and meta-analysis. PloS one, $7(12)$

Van Der Put, C., Gubbels, J., \& Assink, M. (2019). Predicting domestic violence: A meta-analysis on the predictive validity of risk assessment tools. Aggression and ViolentBehavior, 47, 100-116.

Weisz, A. N., Tolman, R. M., \& Saunders, D. G. (2000). Assessing the risk of severe domestic violence: The importance of survivors' predictions. Journal of interpersonal violence, 15(1), 75-90.

White, H. R., \& Chen, P. H. (2002). Problem drinking and intimate partner violence. Journal of studies on alcohol, 63(2), 205-214.

Williams, K. R., \& Grant, S. R. (2006). Empirically examining the risk of intimate partner violence: The Revised Domestic Violence Screening Instrument (DVSIR). Public Health Reports, 121(4), 400-408.

Williams, K. R., \& Houghton, A. B. (2004). Assessing the risk of domestic violence Re-offending: A validation study. Law and human behavior, 28(4), 437-455.

Williams, K. (2012). Family violence risk assessment: A predictive cross-validation study of the Domestic Violence Screening Instrument-Revised (DVSI-R). Law and Human Behavior, 36(2), 120-129.

Williams, K. (n.d.). Disentangling the Risk Assessment and Intimate Partner Violence 96 
Relation: Estimating mediating and moderating effects. Law and Human

Behavior., 41(4), 344-353.

Wolfe, D. A., Crooks, C. V., Lee, V., McIntyre-Smith, A., \& Jaffe, P. G. (2003). The effects of children's exposure to domestic violence: A meta-analysis and critique. Clinical child and family psychology review, 6(3), 171-187. 